Research Paper

\title{
A New and Safe Mode of Ventilation for Interventional Pulmonary Medicine: The Ease of Nasal Superimposed High Frequency Jet Ventilation
}

\author{
Wolfgang Hohenforst-Schmidt ${ }^{1}$, Paul Zarogoulidis ${ }^{2}{ }^{\bowtie}$, Haidong Huang ${ }^{3}$, Yan-Gao Man ${ }^{4}$, Stella Laskou, \\ Charilaos Koulouris, Dimitris Giannakidis, Stylianos Mantalobas, Maria C. Florou ${ }^{5}$, Aikaterini Amaniti ${ }^{6}$, \\ Michael Steinheimer ${ }^{1}$, Anil Sinha ${ }^{1}$, Lutz Freitag7, J Francis Turner ${ }^{8}$, Robert Browning ${ }^{9}$, Thomas Vogl ${ }^{10}$, \\ Andrei Roman ${ }^{10}$, Naim Benhassen ${ }^{11}$, Isaak Kesisoglou ${ }^{5}$, Konstantinos Sapalidis ${ }^{5}$

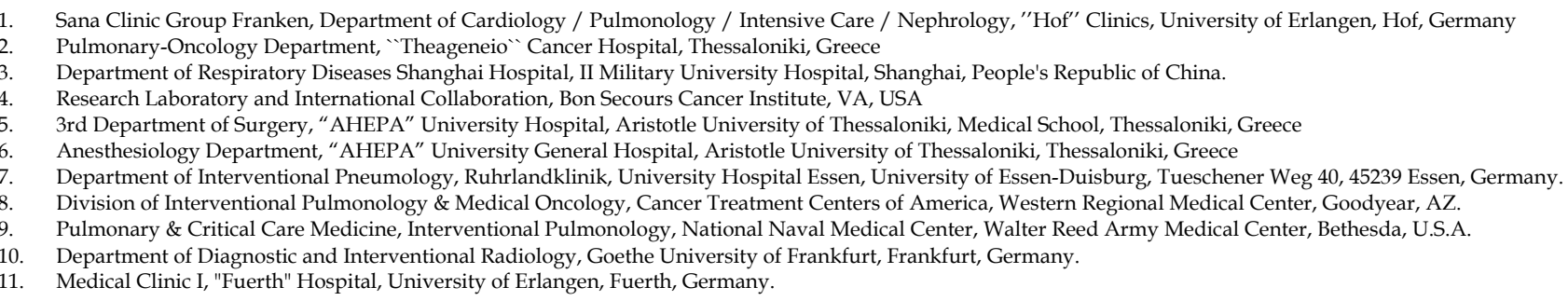

$\triangle$ Corresponding author: Paul Zarogoulidis, MD, Ph. D, Pulmonary-Oncology Department, “Theageneio" Cancer Hospital, Thessaloniki, Greece. Mobile: 00306977271974; E-mail: pzarog@hotmail.com

() Ivyspring International Publisher. This is an open access article distributed under the terms of the Creative Commons Attribution (CC BY-NC) license (https://creativecommons.org/licenses/by-nc/4.0/). See http://ivyspring.com/terms for full terms and conditions.

Received: 2017.11.08; Accepted: 2017.12.03; Published: 2018.02.12

\begin{abstract}
We use pulmonary interventional procedures for the diagnosis of pulmonary diseases either for benign or malignant lesions. Flexible bronchoscopy with or without radial endobronchial ultrasound, convex-probe endobronchial ultrasound and electromagnetic navigation are procedures performed in centers with experience in diagnostic pulmonary medicine. The method of sedation and ventilation-is very important in order to avoid or handle with success complications. Proper respiration during pulmonary (or other interventional) procedures is a key factor. Apart from the proper sedation method we have to choose the proper ventilation method which decides respiratory movement. Superimposed high-frequency jet ventilation (SHFJV) is supposed to be safe and effective in clinical practice. Although this perception is commonly accepted, there is no study proving its safety on the basic of reliable data. We analyzed the data of 100 patients in different interventional settings (bronchoscopy with or without navigational approach, left atrial appendage closure (LAAC) or intracardiac catheterization) using nasal SHFJV. Mainly analyzed were capillary ABG-Data at the beginning and end of the intervention under sedation. The aim was to analyze if a risk scenario for the patient by using the nasal SHFJV can be derived by measuring the changes of $\mathrm{pCO} 2, \mathrm{pO} 2$, cBase Excess, $\mathrm{cHCO} 3$ and $\mathrm{PH}$. Due to our data we conclude that this method of ventilation can be easily and safely used in interventional medicine for patients with all kind of comorbidities such as; chronic respiratory disease, lung cancer, interstitial lung disease, structural heart disease and heart failure.
\end{abstract}

Key words: lung cancer, bronchoscopy, endobronchial navigation, endobronchial ultrasound, interventional medicine, minimal-invasive techniques, conebeam computertomography, jet-ventilation.

\section{Introduction}

The first approaches, to maintain the pulmonary gas exchange without conventional ventilation arose at the beginning of the 20th century and went with the
Volhards animal experimental settings back.[1] 1954 refined Barth the method using the introduction of a oxygen insufflation into the trachea for bridging 
apnea during bronchoscopy and lung resections.[2] The injector method was developed by Sanders end of the sixties. The concept behind that method is to apply breathing gas in portion with high pressure over a fine cannula, which was inserted in a bronchoscope.[3] At this stage, jet ventilation was delivered using only physiological frequencies, which may have disadvantages, like the risk of debris seeding, aspiration of blood as well as undesired vocal cord movements which may impede surgery.[4-6] Sjöstrand and coworkers discovered that it was possible to maintain adequate gas exchange with a high frequency (> $60 \mathrm{~min}-1$ ) and low tidal volume ventilation. $[7,8]$ Klain and Smith developed 1977 the high frequency jet ventilation (HFJV). The HFJV initially was only connected to percutaneous transtracheal catheter. The catheter was connected to an air source that provided a jet injection of air controlled by a fluidic logic ventilator. Rates up to 600 breaths/min $(10 \mathrm{~Hz})$ were used. Later this technique used a catheter that allowed for air entrainment. HFJV offers rates of approximately 100 to 600 breaths/min (1,7 to $10 \mathrm{~Hz}$, respectively) with a volume smaller than anatomic dead space volume.[9]

HFJV might not provide adequate carbon dioxide elimination and oxygenation in patients with severe airway stenosis or other complicating respiratory diseases. To address this problem, the combination of HFJV with a low-frequency jet component (superimposed high-frequency-jet ventilation, SHFJV) has been proposed. This method was developed 1990 by Alexander Aloy and his team. It was first described in the study "Tube-free translaryngeal superposed jet ventilation" published in the Anaesthesist. [10][12]. Superimposed high-frequency jet ventilation (SHFJV) involves simultaneously a normal frequency $\left(12-20 \mathrm{~min}^{-1}\right)$ and a high-frequency jet ventilation (HFJV) $\left(>500 \mathrm{~min}^{-1}\right)$. It may increase end-expiratory lung volume (EELV) and improve oxygenation. The proposed mechanism is a positive end-exspiratory pressure (PEEP) effect by the superimposed high-frequency jet component. Ventilation is usually delivered to the patient via two separate injector lines that are driven by one ventilator, allowing for separate adjustment of variables such as working pressure, inspiratory/ expiratory ratio (I/E ratio), and frequency. Figure 1 shows how the low frequent ventilation causes fluctuations in pressure analogous to conventional ventilation. Its jet frequency ranges regularly from 12-20 impulses per minute $(0,2-0,3 \mathrm{~Hz})$ with a (theoretical) maximum of up to $100 / \mathrm{min}$. It produces an upper pressure plateau.[10] The superimposed high frequency jet gas frequency ranges in general from 100-1500 impulses per minute $(1,6-25 \mathrm{~Hz})$. It produces a lower pressure plateau, which correspond to a positive end-exspiratory pressure (PEEP), however, the upper pressure plateau caused by the normofrequent ventilation is additionally increased by the superposition of high frequencies.[10] An important problem for the evaluation of jet ventilation is that there are no bedside techniques available for measurement of end-expiratory volume, tidal volume (VT), and minute ventilation. The reason for the lack of volumetric techniques is that HFJV is usually applied in open systems in which air entrainment occurs to a varying extent, depending on the route of administration and the degree of airway obstruction, and thus a pneumotachograph will not provide accurate values. Likewise, because of gas leakage and mixing with entrained gas, conventional inert gas methods are unsuitable for the assessment of EELV changes during jet ventilation.[11] Leiter compared systematically in a study published 2012 four modes of jet-ventilation (JV). These are supraglottic superimposed highfrequency jet ventilation (SHFJV-SG), supraglottic normal frequency (NFJV-SG), supraglottic high frequency (HFJV-SG), and infraglottic highfrequency jet ventilation (HFJV-IG). All four modes of HFJV provided adequate ventilation and oxygenation but the use of supraglottic SHFJV produced the largest end-expiratory chest wall volume and tidal volume.[2] Superimposed high-frequency jet ventilation (SHFJV) is supposed to be safe and effective in clinical practice. Although this perception is commonly accepted, there is no study proving its safety based on reliable data. This may be a major reason why this ventilation method despite many years of secure and effective use in clinical practice, still is a rarity in hospitals worldwide. Dedicated publications on nasal jet-catheter ventilation with double frequencies in different interventional settings are extremely rare. Instead of jet-catheter the mainstream of traditional lung centres apply rigid bronchoscopy with anesthesia, although not essentially needed for the intervention. Reports about use in interventional cardiology or radiology are also seldom.

\section{Patients and Methods}

After achieving informed consent from all patients we reviewed the records of 100 patients submitted a flexible bronchoscopy in whom we measured before and after the intervention capillary blood gases with or without dedicated navigation for pulmonary diagnostic approaches, for a left atrial appendage closure (LAAC) or an intracardiac catheterization between 2012 and 2015, all of them treated using nasal SHFJV, in the II Medical Clinic, 
Coburg Hospital, University of Wuerzburg, Coburg, Germany and in the Medical Clinic I, Fuerth Hospital, University of Erlangen, Fuerth, Germany. Patients were arbitrary included. No systematic exclusion of patients took place, the database was an all-comers dataset. All interventions were carried out by the same interventionalist Dr. Wolfgang Hohenforst-Schmidt with a sophisticated dual-frequency nasal jet ventilator (Carl Reiner, Vienna). Major aim was to compare the arterial blood gas (ABG) at the beginning and end of the intervention in order to find out if one can derive a risk scenario for the individual patient. The nasal jet catheter was put through the nose into the trachea. The diameter of the catheter is less than $2 \mathrm{~mm}$ and includes 2 channels. It works as an open ventilation-system. The patients can breathe at any time due to the depth of general sedation without relaxation. Different parameters can be varied such us working pressure, frequencies, PEEP, $\mathrm{FiO} 2$ and Inspiratory : Expiratory ratio (I:E). During the intervention patients were standardly monitored including clinical inspection (thorax excursion, skin color, side stream, auscultation, jet-noise), non-invasive blood pressure measurement and continuous measurement of peripheral oxygen saturation. Sedation was performed with a maximum of $5 \mathrm{mg}$ Midazolam and varying amount of Propofol in order to perform the desired intervention. A capillary arterial blood gas analysis (ABG) was taken at the beginning and end of each intervention. The first $A B G$ was taken while starting the sedation, the patients were awake lying on the table. The ABG directly after intervention was taken while the patients were still deeply sedated, the sedation has been stopped just in this moment, the patient was still on nasal jet-catheter ventilation. Beside $\mathrm{ABGs}$ (ph, $\mathrm{pCO} 2$, $\mathrm{pO}$ 2, cBASE(EcF)C, cHCO3 measured on ABL90 FLEX (Radiometer, Krefeld, Germany) before and after the intervention we recorded the following measurements due to some pre-defined hypothesis at the day of intervention: Age, gender, weight, height, derived Body Mass Index (BMI), duration of intervention by measuring time point of start and end of intervention due to the definition of "before" and ",after", purpose (e.g. 58 navigational endobronchial approaches under conebeam computertomography (CBCT) guidance (of those 17 with an additional navigated transthoracic approach by $\mathrm{CBCT}), 42$ non-navigational purposes (of those 11 other bronchoscopies for lung diseases and 31 intracardiac catheterizations (of those 10 LAAC) ), ejection fraction of the left ventricle in percentage (LVEF) (in all patients) (of those heart failure NYHA class $>1$ in 34 patients), existence of lung disease (72 patients) and / or existence of any structural heart disease (s.h.d.) (65 patients) including disease type according to the patient's record. In total the raw data excel sheet consists of 3300 cells. Table 1.

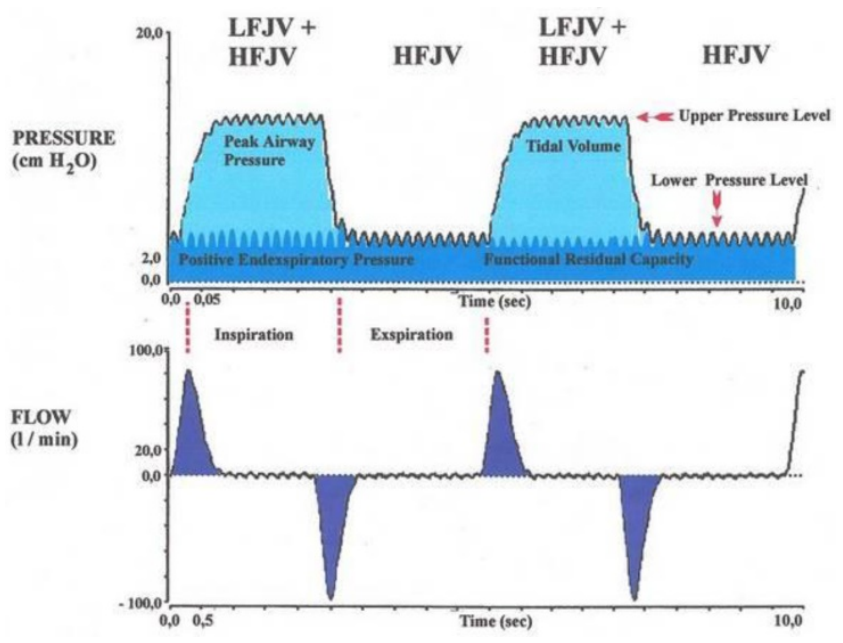

Figure 1: Relation between flow and pressure during inspiration and expiration while ventilation using SHFJV.

Table 1: Structure of the patients

\begin{tabular}{ll}
\hline Characteristics & Number of Patients \\
\hline Male & 66 \\
Female & 34 \\
Age $>50$ & 95 \\
Age $\leq 50$ & 5 \\
BMI $25-30$ & 34 \\
BMI $\leq 25$ & 36 \\
BMI $>30$ & 30 \\
Group A (patients with lung disease) & 72 \\
Group B (patients with a lung disease & 58 \\
undergoing endobronchial navigation & \\
bronchoscopy with conebeam CT) & \\
Group C (patients without & 42 \\
endobronchial navigation) & \\
Group D (patients without lung disease) & 28 \\
Total & 100 \\
\hline
\end{tabular}

In general the modes of each above mentioned group of ventilation were set to achieve unrisky blood gases and hemodynamics according to the publication of Minana et al. [12] with well accepted thresholds for $\mathrm{pO} 2<60 \mathrm{mmHg}, \mathrm{pCO} 2>50 \mathrm{mmHg}$ and $\mathrm{pH}<7,35$. Of note is the fact that during the intervention there was only a live recording of non-invasive oxygen saturation and blood pressure. Therefore the development during intervention of blood gases in regards to the above mentioned thresholds were especially blinded to the figures of $\mathrm{pCO} 2$ and $\mathrm{pH}$.

The above mentioned subgroups were separated due to the fact that endobronchial navigation with CBCT is depending on intermittent low frequency ventilation with a very long inspiratory time (e.g. I:E was set to $2: 1$ with $2 / \mathrm{min}$ ) and higher working 
pressures (e.g. at least 2,5bar in the low frequency jet setting) in order to achieve a maximum tolerable and constant hyperinflation of the lung for dataset acquisition and navigation at the decisive endobronchial path separations: Applying the same hyperinflation pressure mode in acquisition and navigation guarantees a perfect overlay of 2-dimensional fluoroscopy with 3-dimensional segmentation due to the same positionning of the diaphragm.[13] Furthermore it is possible to detect more peripheral airways with hyperinflation as seen in regular thoracical computer tomography. Ventilation mode in group B (with intermittent low frequency hyperinflation) differs therefore from all other groups. In patients with intended diagnostic navigational approach towards a nodule bigger than $9 \mathrm{~mm}$ in all diameters we added onto the endobronchial approach a transthoracic approach when we perceived that we could not reach the nodule in the inner $2 / 3$ of a volume due to anatomy. This transthoracic approach was performed in apnea for dataset acquisition and transthoracic needle puncture which means an additional risk for deteriorated ABG analysis. However, the nasal jet ventilation approach with SHFJV was always adapted to the desired interventional needs. All patients were asked for informed consent and none of the asked all-comers patients were excluded. All interventions were performed without any unintended interruption or major complication like death, pneumothorax, major bleeding, heart attack or intensive care referral. There were no short term (day 30 post intervention) or long term hazard (day 180 post intervention) recorded according to telephone calls with all patients at these days.

\section{Statistical Analysis and Results}

All analyzes were done with SPSS 23.0 and Microsoft Excel 2013, the images were also created with these two programs. The error probability was set at $a=0,05$. The following static methods were used:

Descriptive statistics

- mean, standard deviation, minimum, maximum

- absolute and relative frequencies

- Crosstabs incl. $X^{2}$ tests

Examination of procedural requirements / distribution assumptions

- Kolmogorov-Smirnov test

- Levenés test

Examination of mean differences

- $t$-tests for dependent samples to test mean differences
- t-tests for independent samples (homogene/heterogene variances)

- U-test

- Wilcoxon-Signed-Ranks-test

- Kruskal-Wallis-test

- Simple analysis of variance

- Examination of relationships

- Pearson-correlation

\section{Age and gender}

The sample consists of 100 patients of whom 34 are female and 66 are male. The average age of all patients was 70 years (ys) with a standard deviation (SD) of 11.2 with a minimum age of 23 and a maximum age of 89 . Between female and male there was no significant difference (t-test for independent samples and homogeneous variances, $p=.955)$. In the total sample the age is not normally distributed (Kolmogorov-Smirnov test: $\mathrm{p}=.000$ *). Figure 2,3

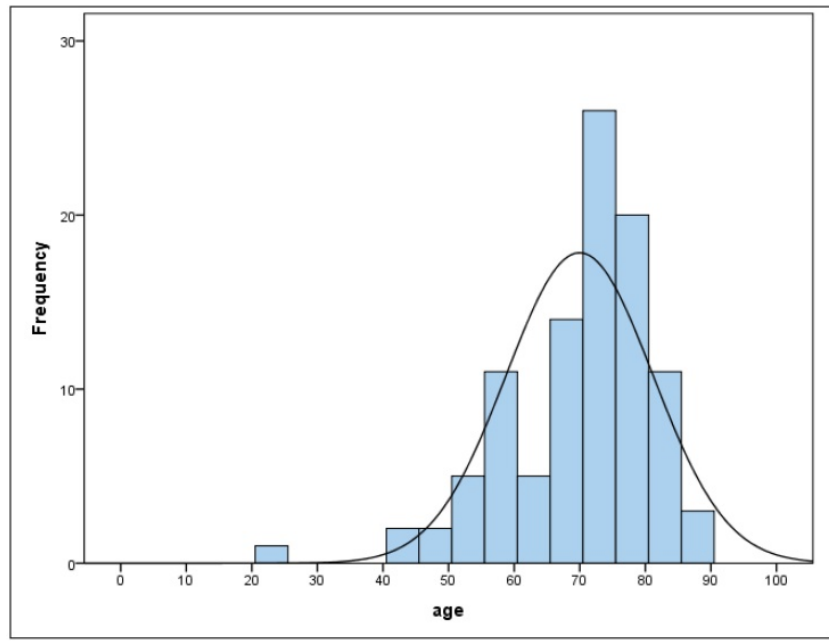

Figure 2: Frequency of age

\section{BMI}

The mean BMI $(\mathrm{kg} / \mathrm{m} 2)$ in the total sample was $27.1(\mathrm{SD}=5.5)$ (Figure 2). There is no gender difference (t-test for independent samples and homogeneous variances, $p=.240$ ). The BMI follows a normal distribution (Kolmogorov-Smirnov test) both in the total sample $(p=0.240)$, as well as in men $(p=$ $0.054)$ and women $(p=0.109)$.

\section{Blood gas analysis (BGA) parameter}

Blood gas parameters were measured as capillary blood gases with ABL90 FLEX and labelled according to the above mentioned definition. 


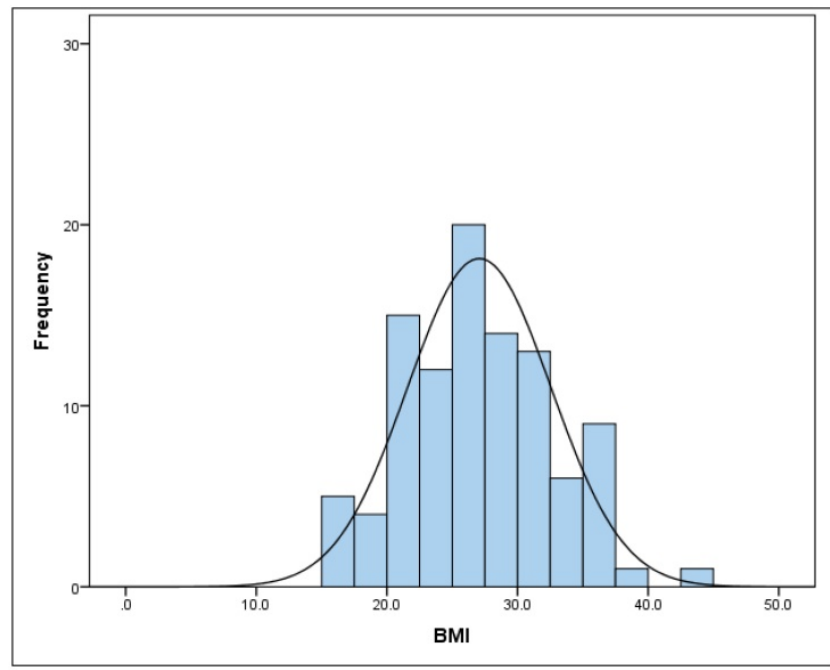

Figure 3: Frequency of BMI

\section{pH}

The $\mathrm{pH}$ was "before" between 7.19 and 7.56, the mean at $7.40(\mathrm{SD}=0.08)$, "after" between 7.07 and 7.66, with the mean decreasing to $7.33(\mathrm{SD}=0.09)$.

The mean drop in the $\mathrm{pH}$ between "before" and "after" is significant (t-test for dependent samples: $p=$ $.000 *$ The average absolute change (difference) was -0.08 , the average percentage change was $-1 \%$ (basis: individual baseline). (Figure 4) The change is therefore significant, but very low.

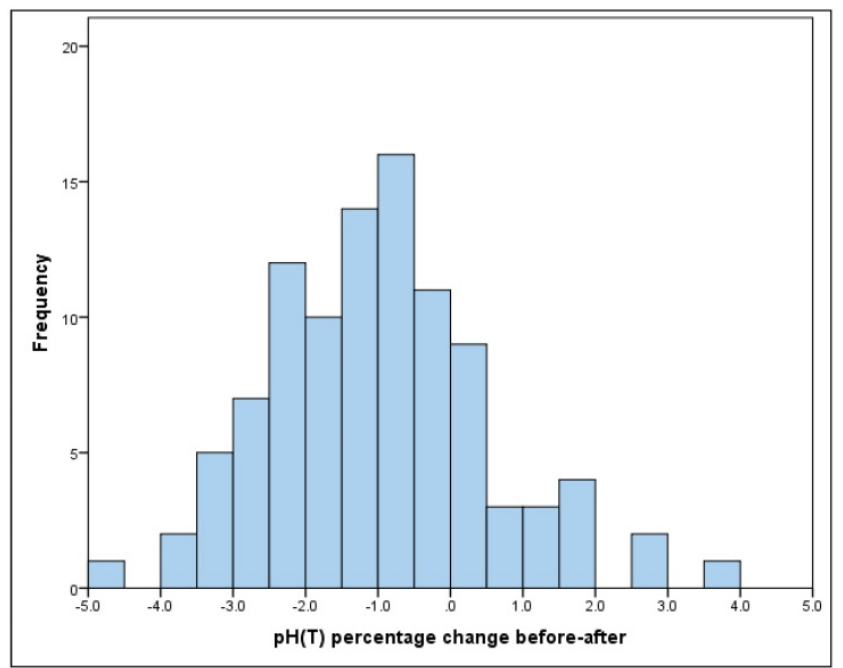

Figure 4: Frequency of $\mathrm{pH}$ percentage change before-after

There is no significant linear relationship between "before" and "after" (Pearson correlation: $\mathrm{r}=$ $0.10, \mathrm{p}=0.302)$.

\section{$\mathrm{pCO}_{2} \mathbf{m m H g}$}

The pCO2 value showed "before" a mean with $42.6 \mathrm{mmHg}(\mathrm{SD}=10.7)$, "after" with a mean rising to $50.7 \mathrm{mmHg}(\mathrm{SD}=13.2$.$) .$
The mean increase in pCO2 between "before" and "after" is significant (t-test for dependent samples: $\mathrm{p}=.000 *$ ) The average absolute change (difference) was $+8.1 \mathrm{mmHg}$, the average percentage change was $+22.8 \%$ (basis: individual initial value). Figure 5 .

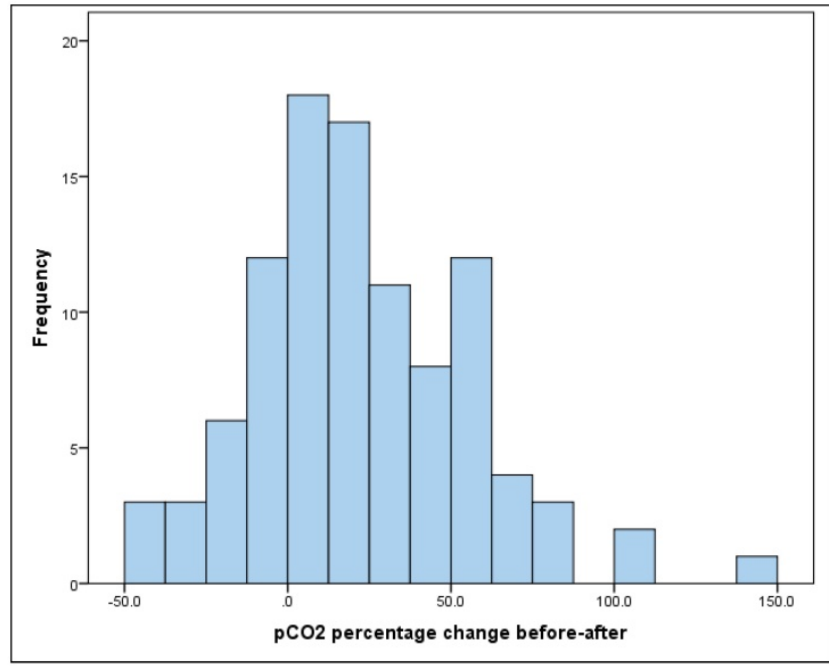

Figure 5. $\mathrm{pCO}_{2}$ percentage change before-after.

There is a significant, but relatively small, linear relationship between pCO2 "before" and "after" of $\mathrm{r}=$ 0.32 (Pearson correlation: $p=0.001^{*}$ ).

\section{$\mathrm{pO}_{2} \mathbf{m m H g}$}

The pO2 value showed "before" a mean at $63.6 \mathrm{mmHg}$ ( $\mathrm{SD}=12.7$ ), "after" a mean rising to $203.1 \mathrm{mmHg}$ (SD = 134.4), which is significant (Wilcoxon-Signed-Ranks-test: $\mathrm{p}=.000$ *)

The average absolute change (difference) was + $139.5 \mathrm{mmHg}$, the average percentage change was + 224.3\% (basis: individual baseline). Closer examination reveals that only $3.0 \%$ of the patients showed a reduction in the $\mathrm{pO} 2$ value, while the remaining $97.0 \%$ showed an increase. The increase showed a mean of $+144.5 \mathrm{mmHg}(\mathrm{SD}=132.1)$. Looking at the relative (percentage) change in the value $\{[100 *[\mathrm{pO} 2$ (after) $-\mathrm{pO} 2$ (before) $]] / \mathrm{pO} 2$ (before) $\}$, the increase was between $+0.7 \%$ and + $907 \%$.

There is no significant relationship between "before" and "after" with $\mathrm{r}=0.15$ (Pearson correlation: $p=0.148)$. Figure 6 .

The scatter plot in Fig. 6 shows the respective values "before" and "after". There one can see very well that the spread "after" is much larger than "before" (SDb = 12.7, SDa = 134.4).

\section{cBase(Ecf)}

The cBase value showed "before" a mean at +1.6 $(\mathrm{SD}=3.4)$, "after" a mean decreasing to $+0.2(\mathrm{SD}=4.7)$, 
The mean decrease in the cBase value between "before" and "after" is significant (Wilcoxon-SignedRanks test: $\mathrm{p}=.000^{*}$ ). Closer inspection reveals that $87 \%$ of patients had a cBase reduction, while the remaining $13 \%$ experienced an increase. The reduction cases showed a mean value of $-2.2(S D=$ 1.5).

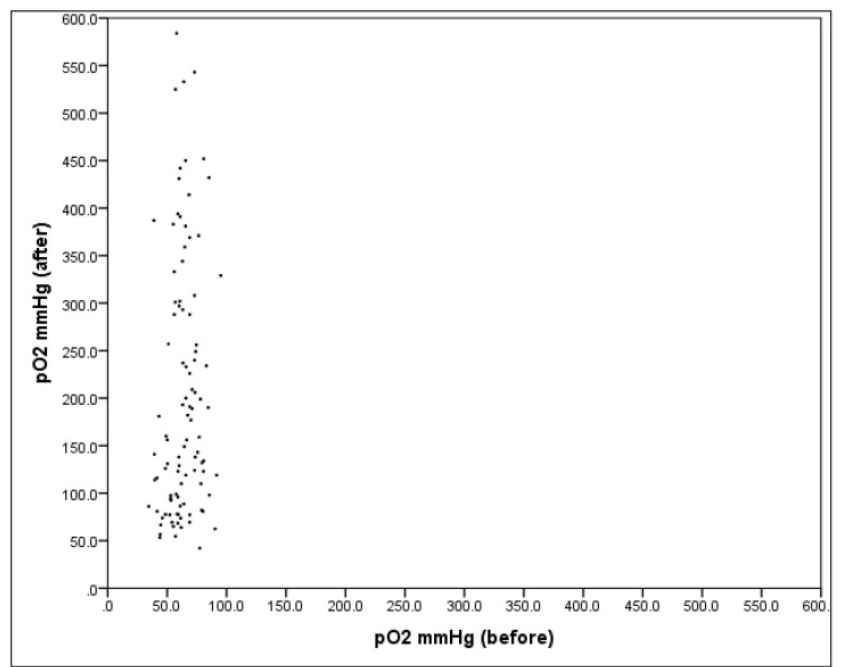

Figure 6: Scatter plot $\mathrm{pO}_{2}$ "before" vs. "after"

Between "before" and "after" there is a mean, relevant and significant linear correlation (correlation according to Pearson: $\mathrm{r}=0.67, \mathrm{p}=0.000$ ). The scatter plot in figure 7 shows the respectively associated values "before" and "after", the structure of the point cloud can be clearly seen here, but also some extreme outliers.

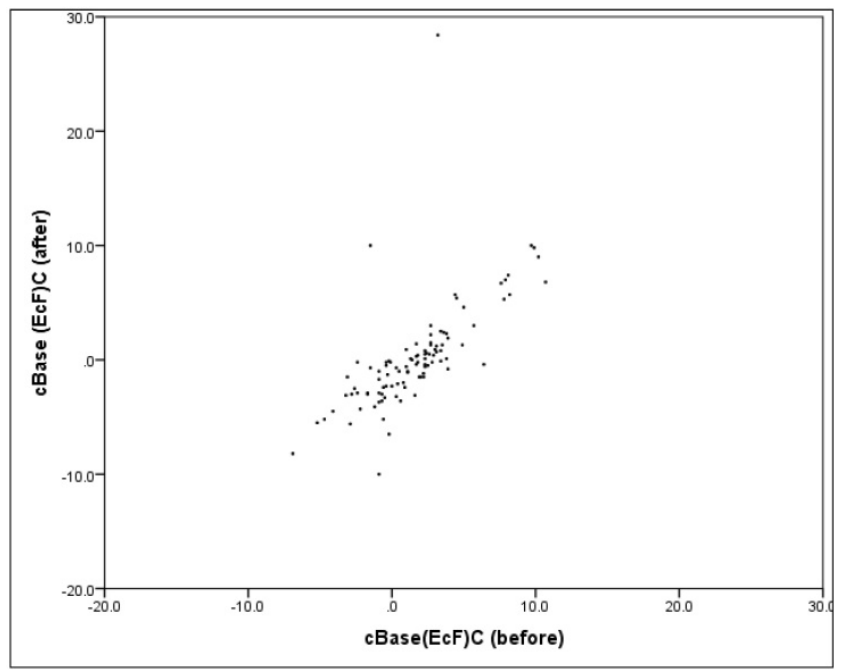

Figure 7: Scatter plot cBase "before" vs. "after".

\section{$\mathrm{CHCO}_{3}(\mathrm{mmol} / \mathrm{l})$}

The HCO3 value showed "before" a mean at 25.6 $(\mathrm{SD}=2.8)$, "after" a mean decreasing to $23.8(\mathrm{SD}=3.2)$.
The mean decrease in the $\mathrm{HCO} 3$ value between "before" and "after" is significant (t-test for dependent samples: $p=.000^{*}$ ), The average absolute change (difference) was $-1.8 \mathrm{mmol} / \mathrm{l}$, the average percentage change was $-6.7 \%$ (basis: individual baseline). A closer look reveals that $86 \%$ of patients had a reduction in $\mathrm{HCO} 3$, while the remaining $14 \%$ experienced an increase. The reduction showed a mean of $-2.4(\mathrm{SD}=$ 1.6). Between "before" and "after" there is a mean, content-relevant and significant linear correlation (correlation according to Pearson: $\mathrm{r}=0.71, \mathrm{p}=$ $\left.0.000^{*}\right)$.The scatter plot in figure 8 shows the respectively associated values "before" and "after", the structure of the point cloud is easy to recognize, but also some outliers.

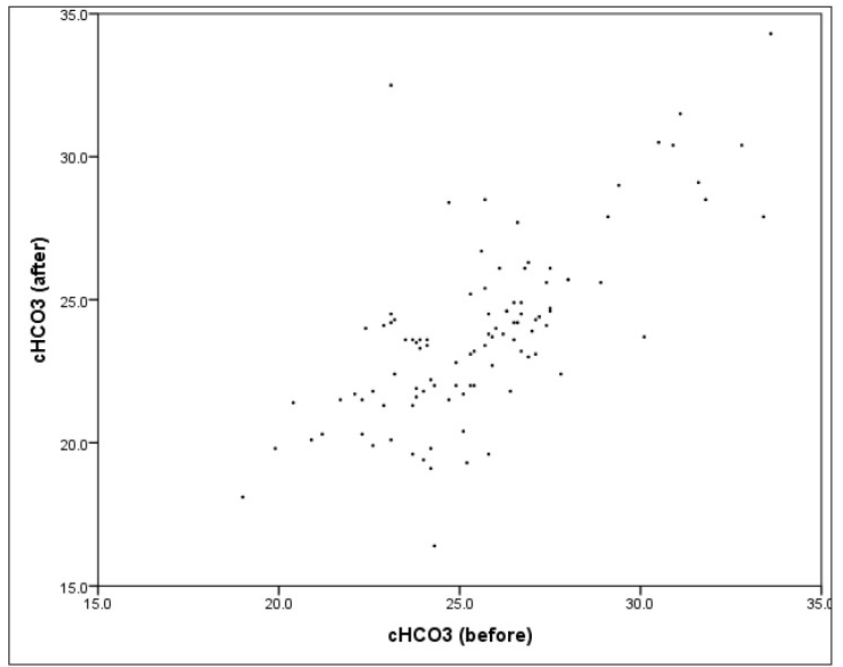

Figure 8. Scatter plot $\mathrm{HCO}_{3}$ "before" vs. "after".

\section{ABG parameters: Examination for a potential risk from nasal jet ventilation.}

Hypothesis A: Jet-ventilation for navigational purpose has a different influence on $\mathrm{pCO} 2$ values after the intervention than jet-ventilation for non-navigational purposes.

This was supposed to be true as for navigation we had to apply intermittent low frequency JV or even apnea. Both settings increase the risk of reduction of CO2-clearance. Table 2.

Between the non-navigational group and the navigational group there are the following descriptions:

a) There is a significant difference in "before" mean values in regards to $\mathrm{pCO} 2$ and $\mathrm{pH}$, but not in pO2.

b) "After" values showed no significant differences in the mean values of all 3 blood gas determinants, especially no difference in $\mathrm{pCO} 2$. 
Table 2. Aa) Consideration of the continuous variables

\begin{tabular}{|c|c|c|c|c|c|}
\hline & \multicolumn{2}{|c|}{$\begin{array}{l}\text { Non-Navigation } \\
(\mathrm{w} / \mathrm{o} \mathrm{CBCT}) \\
(\mathrm{n}=42)\end{array}$} & \multicolumn{2}{|c|}{$\begin{array}{l}\text { Navigation+ } \\
\text { with CBCT } \\
(n=58)\end{array}$} & \multirow{2}{*}{$\begin{array}{l}\begin{array}{l}\text { Mean } \\
\text { differences } \\
\text { (U-test) }\end{array} \\
\mathrm{p}\end{array}$} \\
\hline & mean & SD & mean & SD & \\
\hline pCO2 mmHg (before) & 45.1 & 11.5 & 40.7 & 9.6 & $0.010^{*}$ \\
\hline pO2 mmHg (before) & 61.7 & 11.8 & 65.1 & 13.3 & 0.270 \\
\hline pH (before) & 7.36 & 0.08 & 7.43 & 0.07 & $0.000^{*}$ \\
\hline pCO2 mmHg (after) & 48.4 & 12.8 & 52.4 & 13.3 & 0.182 \\
\hline pO2 mmHg (after) & 195.2 & 121.6 & 209.1 & 144.1 & 0.978 \\
\hline pH (after) & 7.34 & 0.08 & 7.32 & 0.09 & 0.237 \\
\hline $\begin{array}{l}\text { pCO2 difference before/after } \\
\text { absolute }\end{array}$ & 3.3 & 10.5 & 11.7 & 15.4 & $0.001^{*}$ \\
\hline $\begin{array}{l}\text { pO2 difference before/after } \\
\text { absolute }\end{array}$ & 133.5 & 120.5 & 144.0 & 142.8 & 0.876 \\
\hline $\begin{array}{l}\text { pH difference before/after } \\
\text { absolute }\end{array}$ & -0.03 & 0.1 & -.109 & 0.1 & $0.000^{*}$ \\
\hline $\begin{array}{l}\text { pCO2 percentage change } \\
\text { before/after }\end{array}$ & 9.7 & 25.4 & 32.7 & 35.9 & $0.001^{*}$ \\
\hline $\begin{array}{l}\text { pO2 percentage change } \\
\text { before-after }\end{array}$ & 222.8 & 211.3 & 225.4 & 224.3 & 0.762 \\
\hline $\begin{array}{l}\mathrm{pH} \text { percentage change } \\
\text { before-after }\end{array}$ & -0.4 & 1.2 & -1.5 & 1.6 & $0.000^{*}$ \\
\hline
\end{tabular}

c) In both groups there is an increase in the pCO2 mean (the mean of the differences is positive), but the increase in the navigational group is significantly higher (11.7 vs. 3.3mmHg) which was expected. However as mentioned above there is no significant difference in the absolute value of $\mathrm{pCO} 2$ after the intervention in both groups.

d) In both groups there is an increase in the pO2 value (the mean of the differences is positive), but there is no difference between the two groups (the increase is comparably high in both groups).

e) The $\mathrm{pH}$ decreases in both groups (the mean of the differences is negative), but in the navigational group the extent of the $\mathrm{pH}$ reduction is significantly more pronounced $(-1,5, \mathrm{SD}=1,6)$.

The above points apply both to the absolute difference and to the relative (percentage) difference.
$\mathrm{Ab}$ ) Dichotomization of variables (cut-off scores) In the next step, the 3 parameters were dichotomised along the cut-off scores that have been defined in advance:

- $\mathrm{pCO} 2>50 \mathrm{mmHg}$

- $\mathrm{pO} 2<60 \mathrm{mmHg}$

- $\mathrm{pH}<7.35$

Hypothesis B: The initial level of $\mathrm{pCO} 2>50 \mathrm{mmHg}$ has a greater and significant influence in the navigational group.

\section{Abl) $\mathrm{pCO} 2>50 \mathrm{mmHg}$}

In the navigational group "Before" only $8.8 \%$ of patients are found with a pCO2 value $>50 \mathrm{mmHg}$, in the non-navigational group it is $32.6 \%$. The proportion increases to "after" in both groups, with a much more pronounced increase in the navigational group from $8.8 \%$ to $50.9 \%$, while in the non-navigational group it is only from $32.6 \%$ to $41.9 \%$. Figure 9.

If one considers only the sub-sample in which the $\mathrm{pCO} 2$ value was already above the cut-off value at the beginning (pCO2 initial $>50 \mathrm{mmHg}$ ), it turns out that in the non-navigational group, $71.4 \%$ of these patients have reached this cut-off value in the "after" measurement, in the navigation group it is only $60.0 \%$.

Therefore the proportion of patients who are "after" above the pCO2 threshold of $50 \mathrm{mmHg}$ is not different between the navigation and the non-navigational group, but only in the subsample that is "before" already above the cut-off value ( $\mathrm{X}^{2}$ test: $p=0.520)$. Figure 10 .

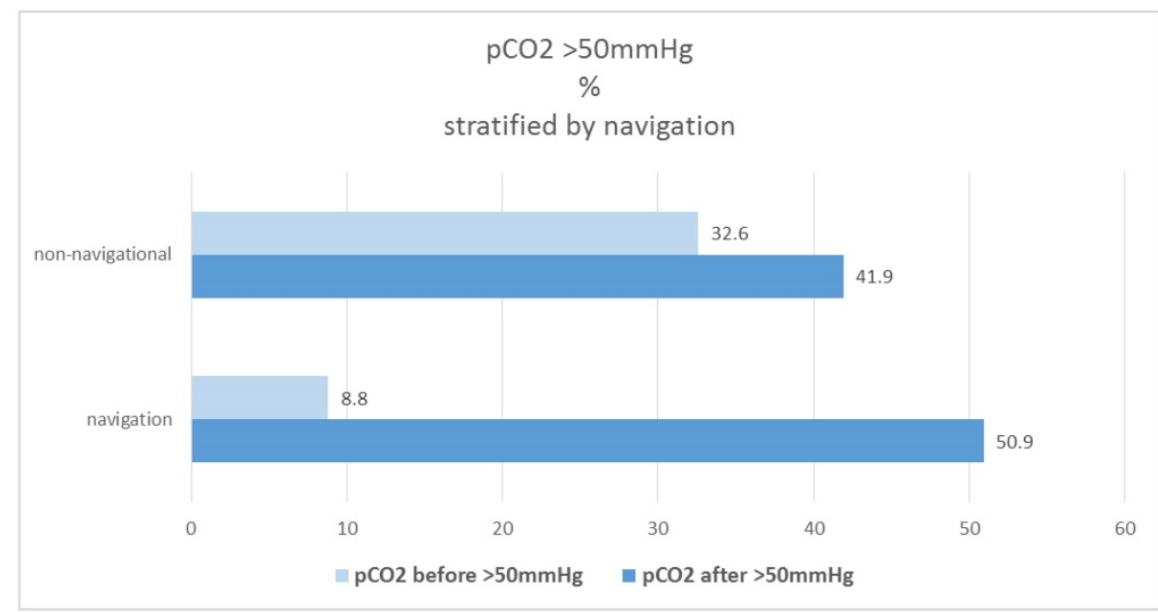

Figure 9. Percentage of patients $\mathrm{pCO}_{2}$ (before/after) $>50 \mathrm{mmHg}$, stratified by navigation 


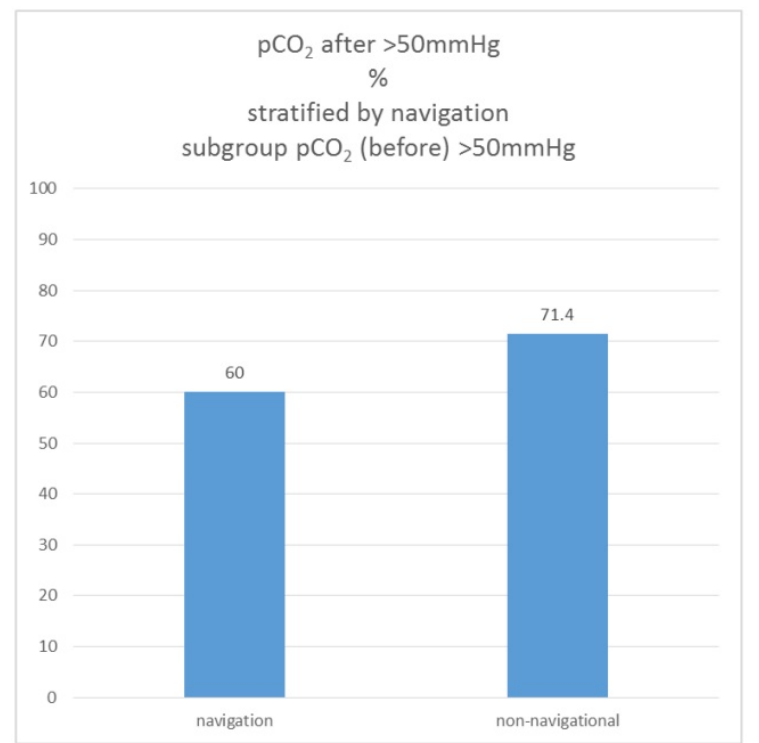

Figure 10. Percentage of patients $\mathrm{pCO}_{2}$ (after) $>50 \mathrm{mmHg}$, subgroup $\mathrm{PCO}_{2}$ (before) $>50 \mathrm{mmHg}$, stratified by navigation.

\section{Abll) $\mathrm{pO} 2<60 \mathrm{mmHg}$}

In the navigation group "Before" there are 36.8\% who have a $\mathrm{pO} 2$ value $<60 \mathrm{mmHg}$, in the non-navigational group it is $39.5 \%$ (no group difference). The proportion falls to "after" in both groups to $2.3 \%$ and $5.3 \%$, therefore the probability of a low pO2 after the intervention with JV is neglectable. The proportion of patients situated "after" below the pO2 threshold of $60 \mathrm{mmHg}$ is not different between navigation and the non-navigational group $\left(\mathrm{X}^{2}\right.$ test: $\mathrm{p}$ $=0.422$ ).

Ablli) $\mathrm{pH}<7.35$

In the navigation group $8.8 \%$, which have a $\mathrm{pH}$ $<7.35$, are found in the "before" category; in the non-navigational group it is $37.2 \%$ (significant group difference: $\mathrm{X}^{2}$-test: $\mathrm{p}=0.0221$ ). The proportion increases to "after" in both groups to $63.2 \%$ and $53.5 \%$. Figure 11.

If only the subsample with the initial $\mathrm{pCO} 2$ value above the cut-off value ( $\mathrm{pCO} 2$ initial $>50 \mathrm{mmHg}$ ) is considered, $57.1 \%$ of these patients in the non-navigational group are "after" below the cutoff value $\mathrm{pH}$ cut-off value, in the navigation group is $40.0 \%$. The group difference is not significant $\left(X^{2}\right.$ test: $\mathrm{p}=0.412)$.

As $\mathrm{pH}$ is clearly depending on $\mathrm{pCO} 2$ it is obvious that the proportion of patients who show "after" a $\mathrm{pH}$ below 7.35 does not differ between the navigation and the non-navigational group $\left(\mathrm{X}^{2}\right.$ test: $\mathrm{p}$ $=0.628)-$ irrespective if the initial $\mathrm{pCO} 2$ is above $50 \mathrm{mmHg}$.

\section{Hypothesis C: Blood gas parameters are depending on LVEF under JV.}

In a first step the ejection classes were formed in 10\% stages. Table 3. Figure 12.

Figure 13. shows the percentage of "critical" patients in the $10 \%$ EF stages.

For $\mathrm{pO} 2$ there are no differences to $\mathrm{EF}$, the proportion is comparably high in all classes (random fluctuations, $\mathrm{X}^{2}$ test: $\mathrm{p}=0.725$ and 0.868 , respectively).

For $\mathrm{pH}$, there are also only random fluctuations, the \% rate of "critical" patients is independent of the EF class ( $X^{2}$ test: $p=0.880$ and 0.188 respectively).

For pCO2 there are also only random fluctuations, the $\%$ set of "critical" patients is independent of the EF class $\left(\mathrm{X}^{2}\right.$ test: $\mathrm{p}=0.360$ and 0.451 respectively).

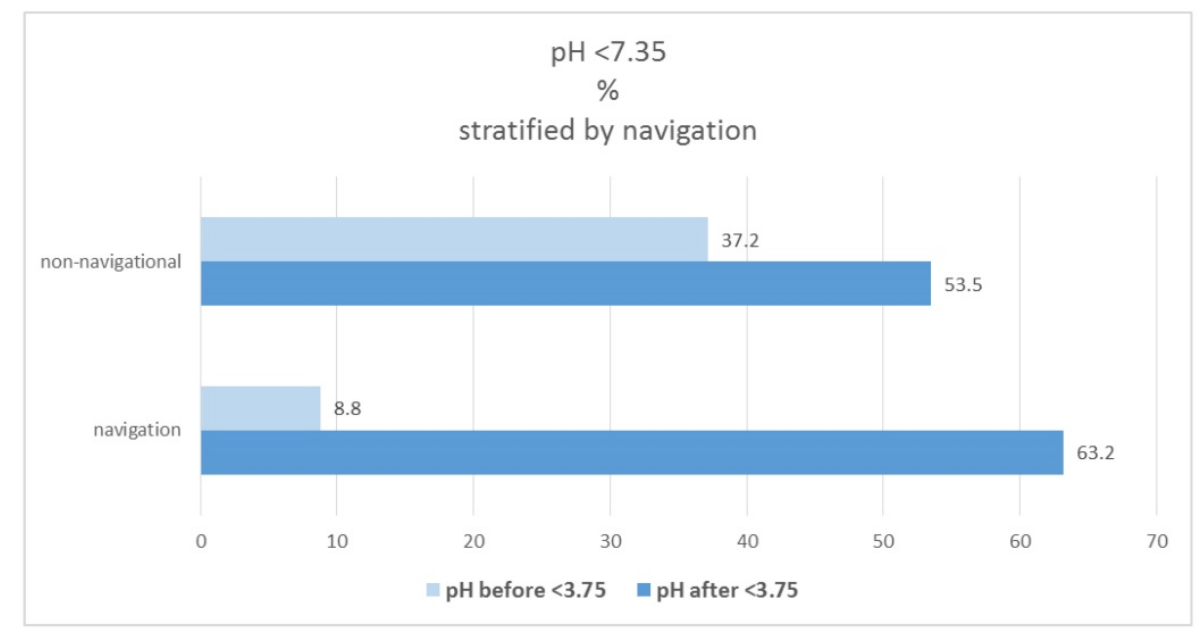

Figure 11. Percentage of patients $\mathrm{pH}$ (before/after) $<7.35$, stratified by navigation. 


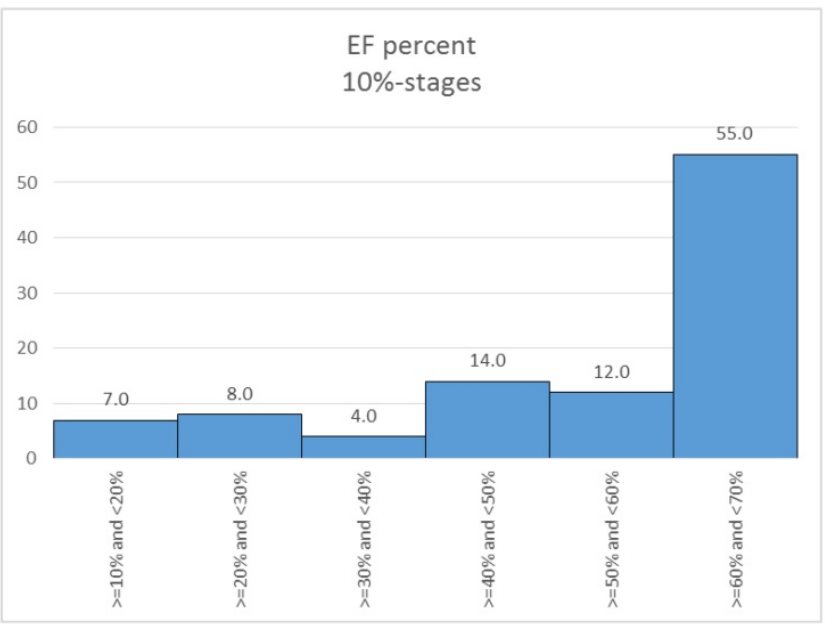

Figure 12. Distribution of EF percent (10\%-stages).
Hypothesis D: A higher BMI is influencing blood gas parameters under JV.

In the first step, the BMI was dichotomized $(\leq 32$ vs.> 32; per definition strong adipositas with a BMI $>32$ ). $20 \%$ of patients fall into the critical stage of BMI> 32, in the navigation group the proportion is $12.3 \%$, in the non-navigational group it is $30.2 \%$.

Table 4.

There is no significant correlation between BMI and $\mathrm{pCO} 2$ ( $\mathrm{X}^{2}$ test: $\mathrm{p}=0.764$ and 0.482 , respectively).

There is no significant correlation between BMI and $\mathrm{pO} 2$ ( $\mathrm{X}^{2}$ test: $\mathrm{p}=0.799$ and 0.379 , respectively).

There is no significant correlation between BMI and $\mathrm{pH}\left(\mathrm{X}^{2}\right.$ test: $\mathrm{p}=0.684$ and 0.717 , respectively).

Table 3. Measurements EF: ejection fraction, partial Ogygene and Carbon Dioxide (before/after)

\begin{tabular}{lllllll}
\hline EF & pCO2 $>$ 50mmHG & pO2<60mmHg & pH<7.35 & pCO2(after) $>$ pCO2(before) & pO2(after)<pO2(before) & pH(after)<pH(before) \\
\hline$>=10 \%$ and $<20 \%$ & $57.1 \%$ & $0.0 \%$ & $57.1 \%$ & $85.7 \%$ & $0.0 \%$ & $85.7 \%$ \\
$>=20 \%$ and $<30 \%$ & $37.5 \%$ & $12.5 \%$ & $75.0 \%$ & $75.0 \%$ & $62.5 \%$ \\
$>=30 \%$ and $<40 \%$ & $100.0 \%$ & $0.0 \%$ & $75.0 \%$ & $100.0 \%$ & $0.0 \%$ & $7.1 \%$ \\
$>=40 \%$ and $<50 \%$ & $42.9 \%$ & $7.1 \%$ & $50.0 \%$ & $57.1 \%$ & $0.0 \%$ & $57.1 \%$ \\
$>=50 \%$ and $<60 \%$ & $50.0 \%$ & $0.0 \%$ & $58.3 \%$ & $83.3 \%$ & $91.7 \%$ \\
$>=60 \%$ and $<70 \%$ & $50.0 \%$ & $3.6 \%$ & $58.2 \%$ & $76.4 \%$ & $80.0 \%$ & $3.6 \%$ \\
\hline
\end{tabular}

Table 4. Whole database $(n=100)$

\begin{tabular}{|c|c|c|c|c|c|c|}
\hline BMI & $\mathrm{pCO} 2>50 \mathrm{mmHG}$ & $\mathrm{pO} 2<60 \mathrm{mmHg}$ & $\mathrm{pH}<7.35$ & pCO2(after)>pCO2(before) & pO2(after) $<$ pO2(before) & $\mathrm{pH}$ (after) $<\mathrm{pH}$ (before) \\
\hline$\leq 32$ & $46.3 \%$ & $3.8 \%$ & $60.0 \%$ & $77.5 \%$ & $3.8 \%$ & $78.8 \%$ \\
\hline$>32$ & $50.0 \%$ & $5.0 \%$ & $55.0 \%$ & $70.0 \%$ & $0.0 \%$ & $75.0 \%$ \\
\hline
\end{tabular}

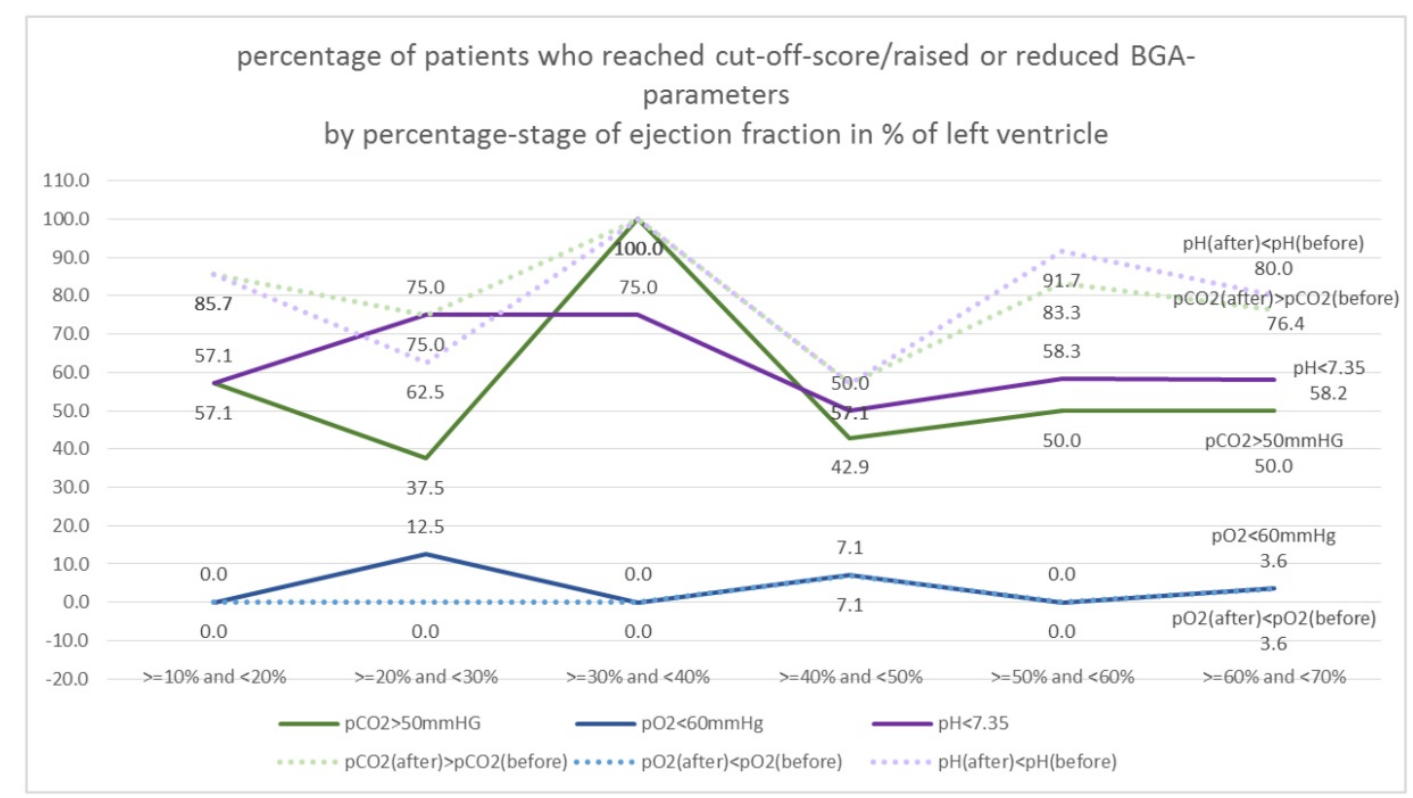

Figure 13. Percentage of patients who reached cut-off-score/raised or reduced BGA-parameters by percentage-stage of ejection fraction in \% of left ventricle (10\%-stages). 
Table 5. Measurements EF: ejection fraction, partial Ogygene and Carbon Dioxide (before/after)

\begin{tabular}{|c|c|c|c|c|c|c|}
\hline EF & $\mathrm{pCO} 2>50 \mathrm{mmHG}$ & $\mathrm{pO} 2<60 \mathrm{mmHg}$ & $\mathrm{pH}<7.35$ & pCO2(after)>pCO2(before) & pO2(after)<pO2(before) & $\mathrm{pH}($ after $)<\mathrm{pH}$ (before) \\
\hline$<60$ years & $38.1 \%$ & $0.0 \%$ & $66.7 \%$ & $81.0 \%$ & $0.0 \%$ & $85.7 \%$ \\
\hline $60-<70$ years & $52.6 \%$ & $0.0 \%$ & $47.4 \%$ & $89.5 \%$ & $5.3 \%$ & $94.7 \%$ \\
\hline $70-<80$ years & $47.8 \%$ & $8.7 \%$ & $58.7 \%$ & $71.7 \%$ & $4.3 \%$ & $69.6 \%$ \\
\hline$\geq 80$ years & $50.0 \%$ & $0.0 \%$ & $64.3 \%$ & $64.3 \%$ & $0.0 \%$ & $71.4 \%$ \\
\hline
\end{tabular}

Hypothesis E: Age increases deterioration of blood gas parameters under JV.

Based on the age distribution of the sample (figure 2), age is categorized into 10-year classes, with 1st grade comprising persons under the age of $60.21 \%$ of patients fall into the category $<60$ years, $19 \%$ are 60 $<70$ years, $46 \%$ are $70-<80$ years and the remaining $14 \%$ are 80 years or older. Table 5.

There is no significant correlation between the age groups and pCO2 $\left(\mathrm{X}^{2}\right.$ test: $\mathrm{p}=0.808$ and 0.298 , respectively).

There is no significant correlation between the age groups and $\mathrm{pO} 2\left(\mathrm{X}^{2}\right.$ test: $\mathrm{p}=0.180$ and 0.379 , respectively).

There is no significant correlation between age groups and $\mathrm{pH}\left(\mathrm{X}^{2}\right.$ test: $\mathrm{p}=0.629$ and 0.107, respectively).

\section{Correlation between $\mathrm{pH}$ change and $\mathrm{pCO} 2$ change.}

The correlation between the before-after $\mathrm{pH}$ change and the before-after $\mathrm{pCO} 2$ change is high (Pearson correlation: $r=-0.913)$ and significant $(\mathrm{p}=$ $0.000 *)$. Figure 14.

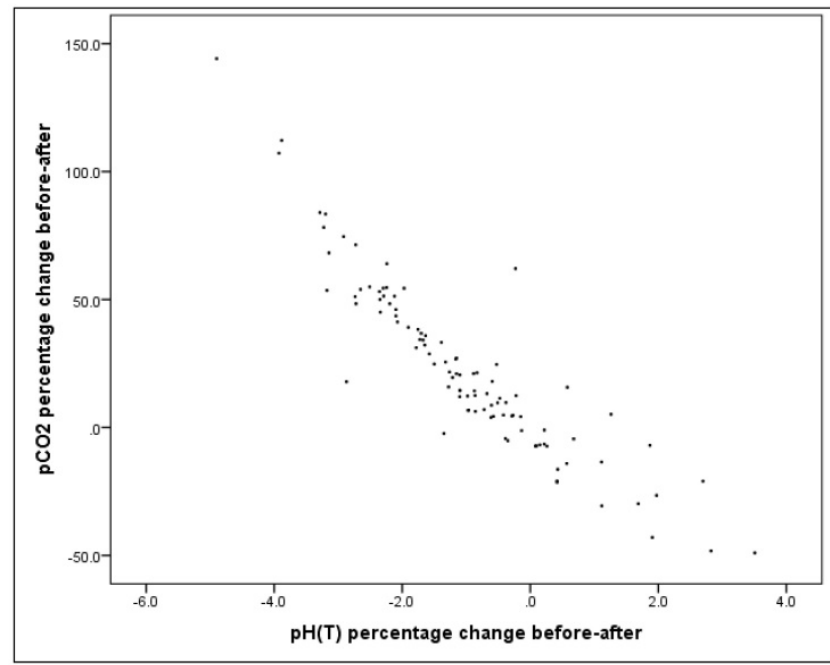

Figure 14. Scatterplot for $\mathrm{pH}$ percentage change and $\mathrm{pCO} 2$ percentage change.

Before the intervention there is a significant correlation between the $\mathrm{pH}$ value and the $\mathrm{pCO} 2$ value (Pearson correlation: $r=-0.803, p=0.000^{*}$ ), as well as "after" the intervention (Pearson correlation: $\mathrm{r}=$
-0.816, $\left.\mathrm{p}=0.000^{*}\right)$, Figures 15-17. Therefore $\mathrm{pH}$ and pCO2 always correlate highly and significantly with each other, in all subsets.

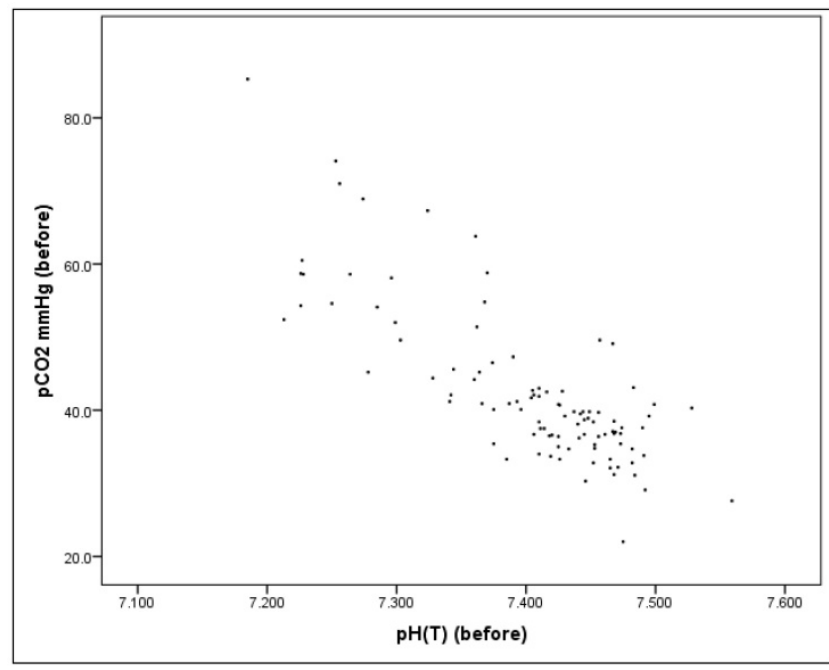

Figure 15. Scatterplot for $\mathrm{pH}$ (before) and $\mathrm{pCO}$ (before).

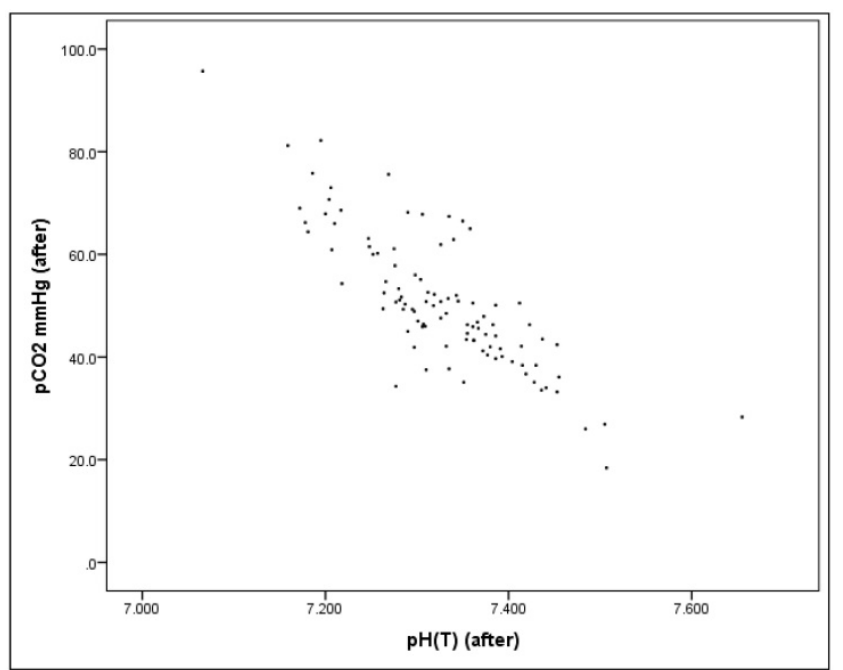

Figure 16. Scatterplot for $\mathrm{pH}$ (after) and $\mathrm{pCO}$ (after)

Hypothesis F: The duration of the intervention has a positive correlation with the level of $\mathrm{pCO} 2$, since $\mathrm{CO} 2$ elimination is a critical function of jet ventilation.

For the whole dataset $(\mathbf{n = 1 0 0 )}$ the linear correlation between the duration (minutes) and the pCO2 value "after" is not significant in univariate analysis $(r=0.034, p=0.739)$, it is no "simple" relationship. 


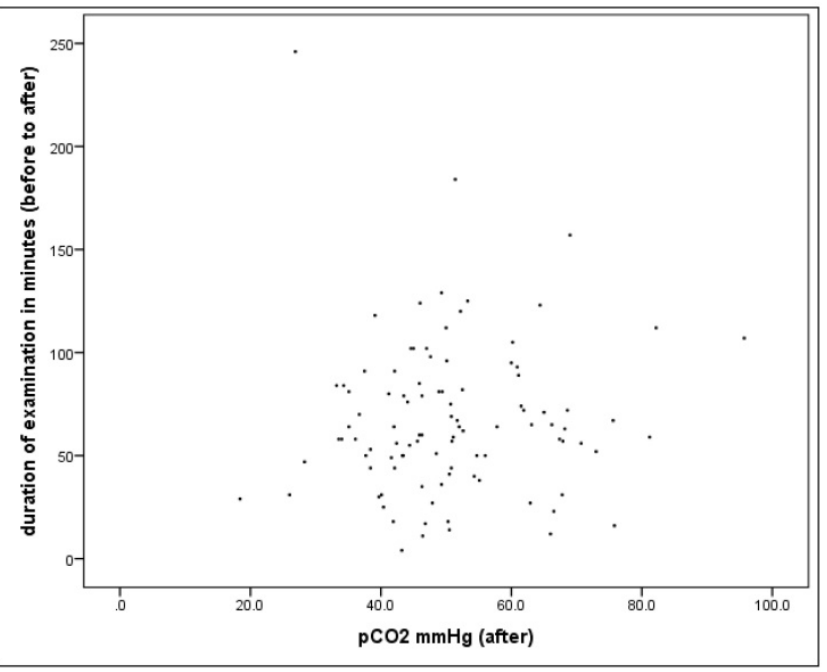

Figure 17. Scatterplot for duration and $\mathrm{pCO} 2$ (after).

Alternatively, if the percent change in the $\mathrm{pCO} 2$ value is considered, the correlation is rather small but significant $(r=0.209, p=0.037)$.

In the next step we have considered the proportion of patients who exceed the critical pCO2 value $(>50 \mathrm{mmHg})$ along a defined time interval. The time intervals in each case comprise 10 minutes, with the 1st interval comprising $<20$ minutes, and the last interval $>=100$ minutes.

There are no differences in the frequency with patients exceeding the critical pCO2 value of $50 \mathrm{mmHg}$ after the intervention as defined between duration classes $\left(X^{2}\right.$-test: $\left.p=0.644\right)$.
72 patients have lung disease. There is also no significant difference in univariate analysis in this subsample $\left(X^{2}\right.$-test: $\left.p=0.768\right)$

\section{Subsamples navigation vs. non-navigational group.}

Dividing the total sample into 2 groups with navigational vs. non-navigational purpose, neither of these two subgroups showed a correlation between duration and $\mathrm{pCO} 2$ (after) $>50 \mathrm{mmHg}\left(\mathrm{X}^{2}\right.$-test: $\mathrm{p}=$ 0.740 and 0.459 , respectively), Figure 18.

\section{Hypothesis G: Lung disease tend to increase pCO2 after the intervention.}

In univariate analysis there is no significant effect of lung disease detectable: In patients without lung disease, the proportion of pCO2> $50 \mathrm{mmHg}$ is $42.9 \%$, and in those with lung disease $48.6 \%$ (t-test for independent samples and homogeneous variances: $p$ $=0.650$ ).

We also looked at the mean $\mathrm{pCO} 2$ values in the two groups. The mean $\mathrm{pCO} 2$ value (after) is $50.16 \mathrm{mmHg}$ in the group without lung disease and $50.90 \mathrm{mmHg}$ in the lung disease group. The mean difference is not significant (t-test for independent samples and homogeneous variances: $p=0.311$ ). The same applies to the percentage change in pCO2, which is $28.3 \%$ for patients without lung disease and $20.7 \%$ for patients with lung disease. The mean difference is also not significant here ( $t$-test for independent samples and homogeneous variances: $p$ $=0.801$ ).

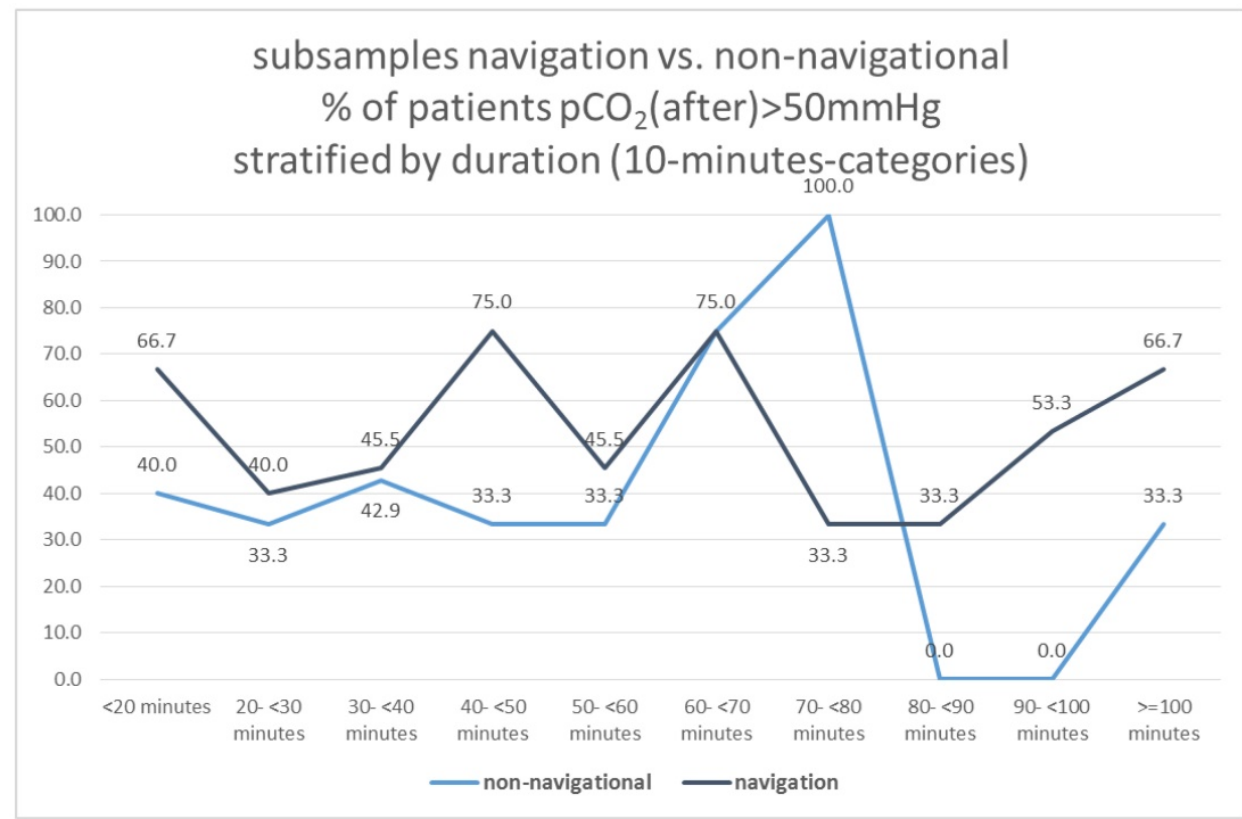

Figure 18. Subsamples navigation vs. non-navigational, $\%$ of patients $\mathrm{pCO} 2$ (after) $>50 \mathrm{mmHg}$ stratified by duration (10-minutes-categories). 
Hypothesis $\mathrm{H}$ : An increased initial pCO2 $>50 \mathrm{mmHg}$ increases the probability of the same value over the above mentioned cut-off after the intervention.

Here is a significant relation. Patients who were above the threshold before intervention showed in $68.4 \%$ of the cases a value above the cut-off score $(50 \mathrm{mmHg})$ after the intervention, patients who were below the threshold before the intervention have only $42.0 \%$ a value $>50 \mathrm{mmHg}\left(\mathrm{p}=0.038^{*}\right)$ after the intervention.

Likewise, there is a significant linear correlation between the "before" and "after" values (raw values of the whole database), as already shown: Between pCO2 "before" and "after" there is a significant, but only relatively linear relationship of $r=0.32$ (Pearson correlation: $\mathrm{p}=0.001^{*}$ ).

\section{Multivariate analysis}

What is promising for jet ventilation (JV) is the different size effects produced between bronchoscopy and catheterization meaning that metric JV attributes can be quantified through the following procedure:

a) Comparative effects between JV modes in groups $A B C$ versus $D$,

b) same effects between groups $B C$ versus $D$ and

c) same effects between groups $\mathrm{BC}$ vs $\mathrm{AD}$.

The mode A alone cannot be discriminated from the rest of the modes, due to the low sample size and perhaps to modest similarities with $\mathrm{BC}$ and also with D. Thus, its effect is deduced subtractive.

d) Most decisive factors for JV technique are history events such as, lung disease and s.h.d., most important gas (really prevailing) is pCO2 and duration of intervention.

c) The reliability of the technique (models under study) was calculated using lift plots and ROC curves (with caution anyway).

Gas variables were relativized to remove individual effects as follows: $\mathbf{V}=(\mathbf{V}$ after $-\mathrm{V}$ before)/V before

The simple change (after - before) does not take into account the initial values which are very different among the patients, causing statistical troubles in the interpretation.

Data after relativization appears very normal apart from $\mathrm{pO} 2$ whose transformation did not help much. Moreover, pO2 did not have any effect on all the various statistical analyses. Table 6. Figure 19.

Gas variables $\mathrm{pCO} 2$ and $\mathrm{pH}$ correlate strongly and negatively $(\mathrm{r}=-0.913)$ as the next figure manifests. Figure 20.

The values of $\mathrm{pH}$ caused enormous problems in the statistical analysis, so it was precluded from further manipulation, but bearing in mind the high correlation with $\mathrm{pCO} 2$, it is easy to conclude an inverse situation whenever $\mathrm{pCO} 2$ is engaged. For instance, an increase of pCO2 corresponds to a decrease in $\mathrm{pH}$ in all statistical analyses following.

The dependent variables were three: Venti (2) (names will be changed upon request) including $\mathrm{ABC}$ and D, Venti (3) including BC and D and finally Venti (5) including $\mathrm{BC}$ and $\mathrm{AD}$.

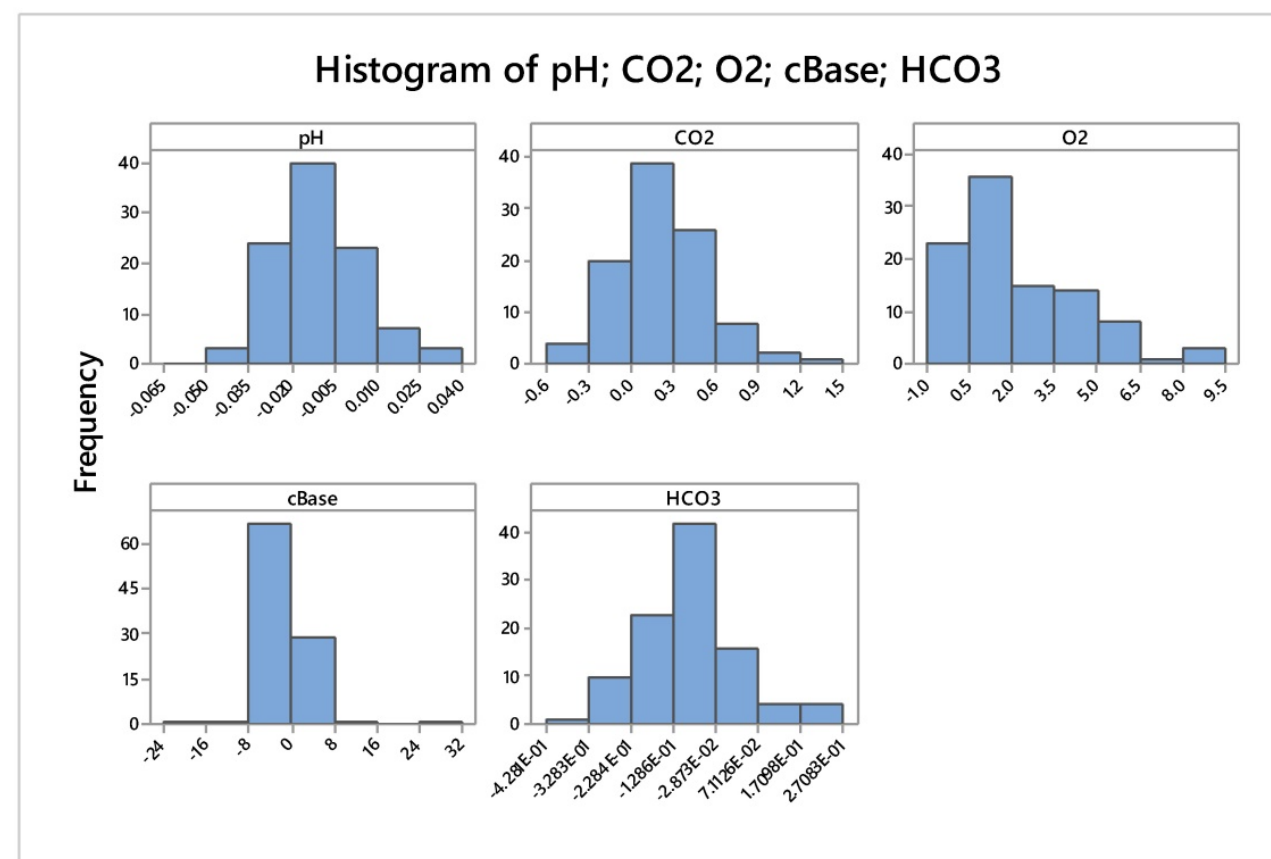

Figure 19. Gas variables were relativized to remove individual effects as follows: $\mathbf{V}=(\mathbf{V}$ after $-\mathbf{V}$ before $) / \mathbf{V}$ before 
Table 6. Descriptive Statistics: $\mathrm{pH}$; $\mathrm{CO} 2$; $\mathrm{O} 2$; $\mathrm{cBase}$; $\mathrm{HCO} 3$ after above mentioned transformation

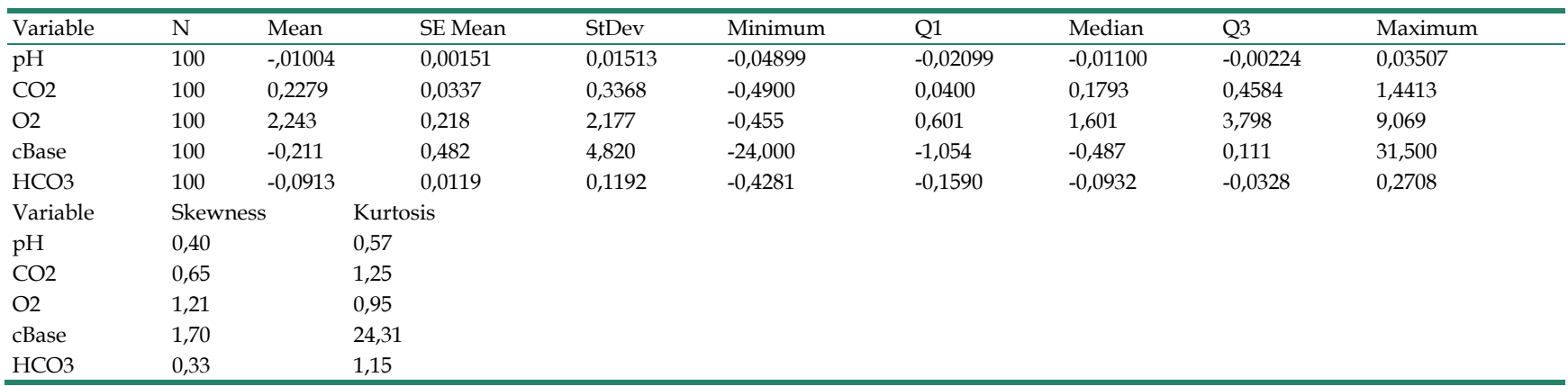

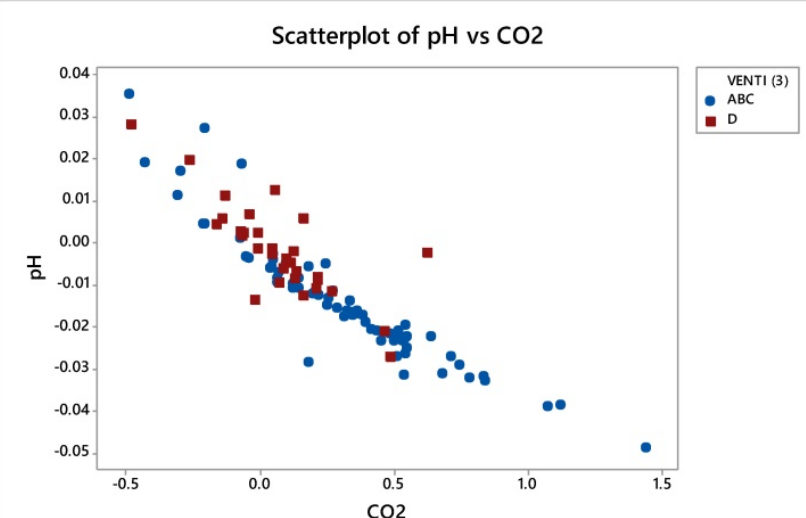

Figure 20. Gas variables $\mathrm{pCO} 2$ and $\mathrm{pH}$ correlate strongly and negatively $(r=-0.913)$ as the next figure manifests.

The predictor variables were:

Quantitative variables: Age, BMI (and coded as well), Duration of intervention (transformed to square root minutes) and the five relativized blood gases.

Coded variables: gender, heart insufficiency, structural heart disease (s.h.d.), lung disease, LVEF dichotomized $(<55 \%$ and $>55 \%)$.

The dependent variables were treated as follows:

First, with multiple discriminant analysis (MDA) in order to find the most effective variables using forward selection of variables (step-wise regression) the power of prediction was tested. This technique was very powerful only for the discrimination between $\mathrm{ABC}$ and $\mathrm{D}$.

The regression and classification of cases technique followed the MDA results, a really innovating statistical tool.

Second, with binary logistic regression (and forward selection) to detect again the most influential variables and also to calculate odds ratios between the two modes under study each time.

Moreover; comparison between $\mathrm{ABC}$ and $\mathrm{D}$ modes. This can be thought as all cases on bronchoscopy approaches versus cardiac catheterization.

Multiple discriminant analysis proved a very efficient technique predicting $91 \%$ of the two classes.
Table 7.

Table 7. Classification Matrix (Spreadsheetl.sta) Classifications: Rows(Observed) Columns(Predicted) (Analysis sample)

\begin{tabular}{llll}
\hline \multirow{3}{*}{ Class } & \multicolumn{3}{l}{ Classification Matrix (Spreadsheet1.sta) Classifications: } \\
& \multicolumn{1}{l}{ Rows(Observed) Columns(Predicted) (Analysis sample) } \\
\cline { 2 - 4 } & Percent & $\mathrm{ABC}$ & $\mathrm{D}$ \\
& Correct & $\mathrm{p}=.6900$ & $\mathrm{p}=.3100$ \\
\hline $\mathrm{ABC}$ & 95.65217 & 66.00000 & 3.00000 \\
$\mathrm{D}$ & 80.64516 & 6.00000 & 25.00000 \\
Total & 91.00000 & 72.00000 & 28.00000 \\
\hline
\end{tabular}

Three patients were mismatched from the $A B C$ group and 6 from the $\mathrm{D}$ group.

Lung disease was the most prevailing discriminant variable (expected so) in joint with operational duration (square root in min), then s.h.d, pCO2, and the interaction between $\mathrm{EF} \%$ and s.h.d.

Table 8. Multivariate Tests of Significance (Spreadsheetl.sta) Sigma-restricted parameterization Effective hypothesis decomposition

\begin{tabular}{lllllll}
\hline \multirow{2}{*}{ Effect } & \multicolumn{6}{l}{$\begin{array}{l}\text { Multivariate Tests of Significance (Spreadsheet1.sta) } \\
\text { Sigma-restricted parameterization Effective hypothesis } \\
\text { decomposition }\end{array}$} \\
\cline { 2 - 8 } & Test & Value & F & $\begin{array}{l}\text { Effect } \\
\text { df }\end{array}$ & $\begin{array}{l}\text { Error } \\
\text { df }\end{array}$ & p \\
\hline s.h.d. & Wilks & 0.906355 & 9.60880 & 1 & 93 & 0.002562 \\
Lung disease & Wilks & 0.564719 & 71.68370 & 1 & 93 & 0.000000 \\
EF-2*s.h.d. & Wilks & 0.915636 & 8.56875 & 1 & 93 & 0.004299 \\
sqrtmin & Wilks & 0.855760 & 15.67536 & 1 & 93 & 0.000147 \\
"CO2" & Wilks & 0.926259 & 7.40393 & 1 & 93 & 0.007769 \\
"HCO3" & Wilks & 0.958583 & 4.01821 & 1 & 93 & 0.047919 \\
\hline
\end{tabular}

Lung disease dominates in the $\mathrm{ABC}$ group presenting 61 patients and only 11 in the $\mathrm{D}$ group. On the other hand, s.h.d. clearly represents the D group (28 patients) and also $53.5 \%$ of the $\mathrm{ABC}$ patients $(37 / 69)$. That means lung diseases play a crucial role in the ventilation effect indifferent if we consider navigation or not. Table 9.

The latter portion is nearly equally divided into $\mathrm{ABC}$ patients suffering from either low or high $\mathrm{EF} \%$ levels (23 against 27 and 9 against 10) in the event of s.h.d. Of note is that much higher incidence $(64.3 \%=18 / 28)$ occurs in patients suffering from 
structural heart disease and low ejection fraction $(<55 \%)$. Thus s,h,d, appears to be a good discriminant variable when only $\mathrm{D}$ patients are recorded for jet ventilation. Patients with a lung disease usually have a heart condition which may affect their ventilation.

Table 10.

Table 9. lung diseases play a crucial role in the ventilation effect indifferent if we consider navigation or not

\begin{tabular}{llll}
\hline s.h.d & ABC & D & All \\
\hline 0 & 32 & 3 & 35 \\
1 & 37 & $\mathbf{2 8}$ & 65 \\
$\mathrm{~N}$ & 69 & 31 & 100 \\
& & & \\
lung dis. & $\mathrm{ABC}$ & $\mathrm{D}$ & All \\
0 & 8 & 20 & 28 \\
1 & $\mathbf{6 1}$ & 11 & 72 \\
& 69 & 31 & 100 \\
\hline
\end{tabular}

Table 10. The division of patients to $A B C$ and $D$ group was further quantified using the classification algorithm proposed by Breimen

\begin{tabular}{lllll}
\hline s.h.d. & $\mathrm{EF} \%$ & $\mathrm{ABC}$ & $\mathrm{D}$ & All \\
\hline 0 & $<55 \%$ & 9 & 1 & 10 \\
& $>55 \%$ & $\mathbf{2 3}$ & 2 & 25 \\
1 & $<55 \%$ & 10 & $\mathbf{1 8}$ & 28 \\
& $>55 \%$ & $\mathbf{2 7}$ & 10 & 37 \\
& All & 69 & 31 & 100 \\
\hline
\end{tabular}

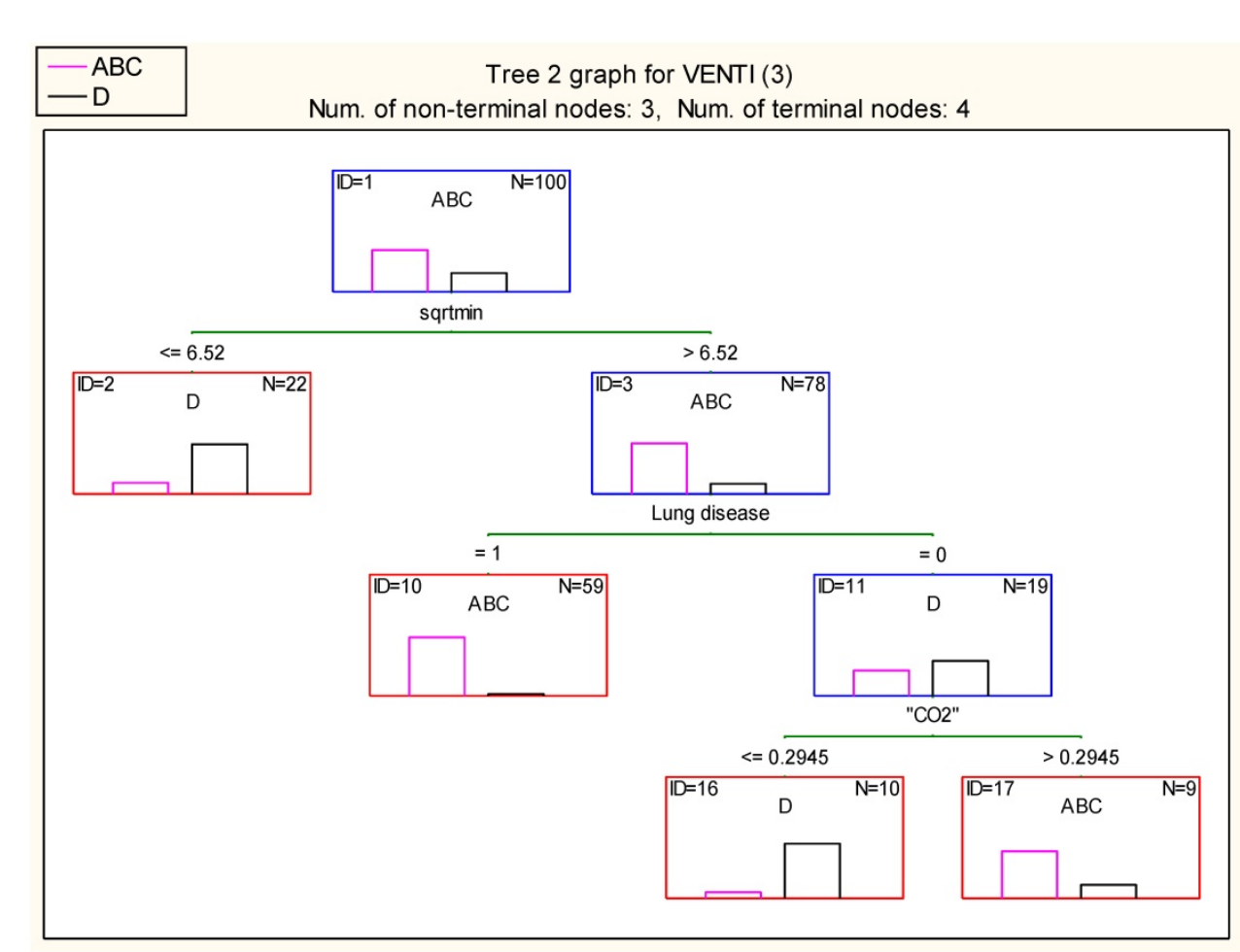

Figure 21. Minor misclassification of cases in each terminal node exists as the following table shows. 
Table 11. Result of terminal nodes 2 (Spreadsheetl.sta) Dependent variable: VENTI (3) Options: Categorical response, Tree number 2

\begin{tabular}{llll}
\hline \multirow{2}{*}{ Node \# } & \multicolumn{4}{l}{ Result of terminal nodes 2 (Spreadsheet1.sta) Dependent variable: } \\
\cline { 2 - 4 } & VENTI (3) Options: Categorical response, Tree number 2 \\
\cline { 2 - 4 } & Class & Class & Gain \\
\hline 2 & 4 & D & 22.00000 \\
10 & 57 & 2 & 59.00000 \\
16 & 1 & 9 & 10.00000 \\
17 & 7 & 2 & 9.00000 \\
\hline
\end{tabular}

Table 12. The model predicts $94.12 \%$ of the ABC cases (64 out of 69 ) and $84.38 \%$ of the D cases ( 27 out of 31 ), see below.

\begin{tabular}{lllll}
\hline & \multicolumn{3}{l}{$\begin{array}{l}\text { Classification matrix 2 (Spreadsheet1.sta) Dependent } \\
\text { variable: VENTI (3) Options: Categorical response, }\end{array}$} \\
\cline { 2 - 5 } Analysis sample & \multicolumn{2}{l}{} \\
\cline { 2 - 4 } & Observed & Predicted ABC & Predicted D & Row Total \\
\hline $\begin{array}{l}\text { Number } \\
\text { Column }\end{array}$ & & 64 & 5 & 69 \\
$\begin{array}{l}\text { Percentage } \\
\text { Row Percentage }\end{array}$ & $94.12 \%$ & $15.63 \%$ & \\
Total Percentage & & $92.75 \%$ & $7.25 \%$ & \\
Number & D & $64.00 \%$ & $5.00 \%$ & $69.00 \%$ \\
Column & & 4 & 27 & 31 \\
Percentage & & $5.88 \%$ & $84.38 \%$ & \\
Row Percentage & & $12.90 \%$ & & \\
Total Percentage & & $4.00 \%$ & $27.10 \%$ & \\
Count & All Groups & 68 & $32.00 \%$ & $31.00 \%$ \\
Total Percent & & $68.00 \%$ & $32.00 \%$ & 100 \\
\hline
\end{tabular}

\section{Interpretation:}

For coded variables (italic) the expression holds as follows (remember we compare $\mathrm{ABC}$ group versus D group):

Patients belonging to $\mathrm{ABC}$ group have 180.7 (times) higher probability to suffer from lung disease than those belonging to group D. Lung disease has a 180.7 higher probability of occurrence in the ABC group rather than in the D group of patients. Table 13.

Patients of ventilation mode ADC will be recorded with structural heart disease 0.131 times more than patients of group D. Because the odds is lower than one you would better comment the inverse situation simply by inverting the odds value: $1 / 0.131=7.63$. That is, D-patients have 7.63 times higher probability of carrying s.h.d as compared to ABC-patients.

For quantitative variables (blue color), the unit of measurement plays important role. Thus for instance, if the length of operational time increases by 1 sqrt minute, the odds that the patient will be classified as $\mathrm{ABC}$ increases by 1.78 times (78\%). Similarly, if the relative percentage change of $\mathrm{pCO} 2$ increases by $1 \%$, the odds that the patient will be classified as $\mathrm{ABC}$ increases by 1.05 times (5\%).

Table 13. Binary regression

\begin{tabular}{|c|c|c|c|c|c|c|c|c|}
\hline ABC/D & $\mathrm{R}^{2}=58.68 \%$ & $N=69 / 31$ & & & & & & \\
\hline Term & Coef & SE Coef & $95 \%$ CI & Odds ratio & $95 \%$ CI & Z-Value & P-Value & VIF \\
\hline sqrtmin & 0.576 & 0.183 & $0.219-0.934$ & 1.78 & $1.24-2.55$ & 3.16 & 0.002 & 1.68 \\
\hline $\mathrm{CO} 2 \%$ & 0.048 & 0.015 & $0,018-0.077$ & 1.05 & $1.018-1.080$ & 3.15 & 0.002 & 1.59 \\
\hline \multicolumn{9}{|c|}{ Lung disease } \\
\hline 1 & 5.20 & 1.17 & $2.89-7.50$ & 180.7 & 18.1- 1805.7 & 4.42 & 0.000 & 2.31 \\
\hline \multicolumn{9}{|c|}{ s.h. disease } \\
\hline 1 & -2.03 & 1.03 & $-4.05--0.01$ & 0.131 & $0.017-0.986$ & -1.97 & 0.048 & 1.27 \\
\hline BC/D & $\mathrm{R}^{2}=67.57 \%$ & $N=57 / 31$ & & & & & & \\
\hline Term & Coef & SE Coef & $95 \%$ CI & Odds ratio & $95 \% \mathrm{CI}$ & Z-Value & P-Value & VIF \\
\hline sqrtmin & 0.608 & 0.211 & 0.195- 1.021 & 1.84 & $1.21-2.78$ & 2.89 & 0.004 & 1.89 \\
\hline $\mathrm{CO} 2 \%$ & 0.074 & 0.023 & $0.029-0.119$ & 1.08 & $1.029-1.126$ & 3.19 & 0.001 & 2.29 \\
\hline \multicolumn{9}{|c|}{$\overline{\text { Lung disease }}$} \\
\hline 1 & 6.14 & 1.69 & $2.82-9.45$ & 463.1 & $16.8-12764.0$ & 3.63 & 0 & 3.28 \\
\hline \multicolumn{9}{|c|}{ s.h. disease } \\
\hline 1 & -2.94 & 1.45 & $-5.79--0.10$ & 0.053 & $0.003-0.908$ & -2.03 & 0.043 & 1.77 \\
\hline \multicolumn{9}{|c|}{ Coded EF-2 } \\
\hline$>55 \%$ & 2.099 & 0.981 & $0.176-4.022$ & 8.16 & $1.19-55.83$ & 2.14 & 0.032 & 1.33 \\
\hline BC/AD & $\mathrm{R}^{2}=32.96 \%$ & $N=57 / 43$ & & & & & & \\
\hline Term & Coef & SE Coef & $95 \%$ CI & Odds ratio & $95 \%$ CI & Z-Value & P-Value & VIF \\
\hline sqrtmin & 0.473 & 0.136 & $0.205-0.740$ & 1.605 & $1.228-2.096$ & 3.47 & 0.000 & 1.19 \\
\hline $\mathrm{CO} 2 \%$ & 0.026 & 0.0087 & $0.009-0.040$ & 1.026 & $1.009-1.040$ & 3.02 & 0.001 & 1.09 \\
\hline \multicolumn{9}{|c|}{$\overline{\text { Lung disease }}$} \\
\hline 1 & 2.766 & 0.699 & $1.396-4.136$ & 15.90 & 4.04- 62.56 & 3.96 & 0 & 1.29 \\
\hline
\end{tabular}


We address below the common predictor existed in the three models.

Comparative relationships between the three binary variables as affected by their common predictors. Table 14.

Table 14. Comparative relationships between the three binary variables as affected by their common predictors.

\begin{tabular}{llll}
\hline Mode & sqrtmin & CO2 & Lung disease (1) \\
\hline ABC/D & 1.78 & 116.2 & 180.7 \\
BC/D & 1.84 & 1600.1 & 463.1 \\
BC/AD & 1.60 & 13.9 & 15.9 \\
\hline
\end{tabular}

Obviously, judging from the values in the table, see mode $\mathrm{A}$; affects strongly negatively pCO2, reduces the operational time and loosely connects with historical lung disease.

The use of navigation is indifferent for the ventilation of the patient during the procedure.

As one has already realized in univariate analysis BMI, age and sex are not involved in the statistical results simply because the stepwise regression rejected those variables in all cases.

The models differed also in the prediction of the classified classes. Table 15.

Table 15. classified classes

\begin{tabular}{|c|c|c|c|}
\hline \multicolumn{4}{|c|}{ ABC/D (good prediction) } \\
\hline & \multicolumn{3}{|c|}{$\begin{array}{l}\text { Classification of cases (Spreadsheet1.sta) Odds ratio } \\
53.333333 \text { Log odds ratio: } 3.976562\end{array}$} \\
\hline & Predicted: ABC & Predicted: D & Percent correct \\
\hline Observed: ABC & 64 & 5 & 92.7536232 \\
\hline Observed: D & 6 & 25 & 80.6451613 \\
\hline \multicolumn{4}{|c|}{ BC/D (excellent prediction) } \\
\hline & \multicolumn{3}{|c|}{$\begin{array}{l}\text { Classification of cases (Spreadsheet2.sta) Odds ratio: } \\
\text { 123.666667 Log odds ratio: } 4.817590\end{array}$} \\
\hline & Predicted: D & Predicted: BC & Percent correct \\
\hline Observed: D & 28 & 3 & 90.3225806 \\
\hline Observed: BC & 4 & 53 & 92.9824561 \\
\hline \multicolumn{4}{|c|}{$\mathrm{BC} / \mathrm{AD}$ (modest prediction but still good enough) } \\
\hline & \multicolumn{3}{|c|}{$\begin{array}{l}\text { Classification of cases (Spreadsheet1.sta) Odds ratio } \\
\text { 18.452381 Log odds ratio: } 2.915193\end{array}$} \\
\hline & Predicted: BC & Predicted: AD & Percent correct \\
\hline Observed: BC & 50 & 7 & 87.7192982 \\
\hline Observed: AD & 12 & 31 & 72.0930233 \\
\hline
\end{tabular}

\section{Conclusions}

In the everyday practice pulmonary physicians use endoscopic procedures in order to diagnose mainly lung cancer. The main diagnostic endoscopic procedures are flexible bronchoscopy with or without radial-ebus [14], convex-probe ebus [15-17], flexible bronchoscopy with electromagnetic navigation and / or conebeam CT. $[13,14,18]$ In order to perform these procedures we choose the proper sedation and ventilation method according to the site of the lesion and clinical characteristics of the patient. In specific comorbidities, such as chronic obstructive pulmonary disease, central mass, chronic heart failure and pleural/pericardial effusion are taken into account before performing the endoscopy. We want to avoid in most of our patients long term sedation mainly due to the underlying comorbidities which were previously described, however; at the same time we have to keep the airways open which is mainly accomplished when a rigid bronchoscope or a tracheal tube is used. Figure 22,23

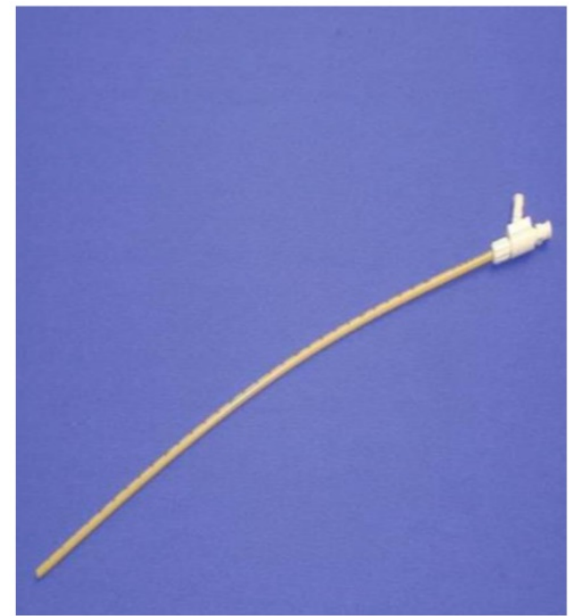

Figure 22. Jet-Nasal Catheter, red arrow indicates the connection point with the ventilator

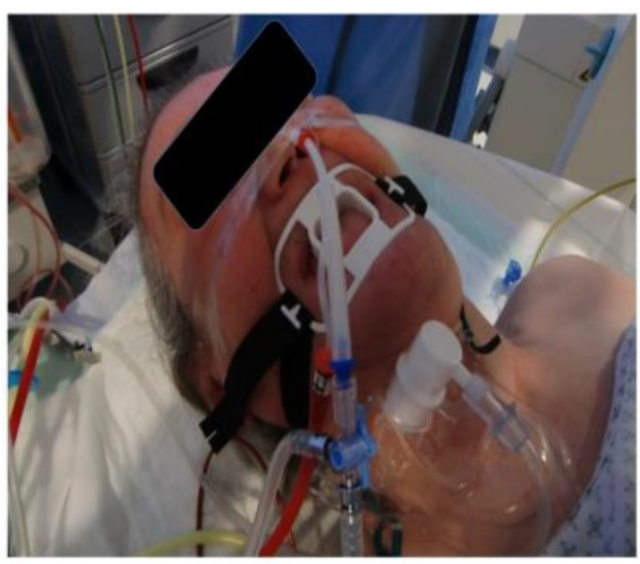

Figure 23. Patient with jet nasal catheter sedated during a diagnostic procedure.

The main issue during endoscopic procedures is to keep the $\mathrm{pCO}_{2}$ values as low as possible in order to prevent acidosis and at the same time to keep the $\mathrm{pO} 2$ sufficiently high.

According to the above mentioned detailed analysis in 100 all-comers real world patients undergoing SHFJV in interventional pulmonology, radiology or cardiology procedures we can state the following conclusions in regards to the above mentioned and well accepted safety thresholds:

I) Age, gender, BMI and LVEF did not show any 
effect in univariate or multivariate analysis in regards to the risk-thresholds of JV. This was especially surprising for BMI and LVEF.

II) As expected $\mathrm{pCO} 2$ was significantly and strongly correlated to $\mathrm{pH}$. This statement is true for all measurements before and after intervention in all subsets of this database. Therefore high initial pCO2 values has a significant influence on the same value after the intervention. By lowering this parameter before any intervention in the sense of optimization it is possible to reduce the risk of $\mathrm{JV}$ in interventional medicine.

III) Although JV for navigational purposes as described with $\mathrm{CBCT}$ raise $\mathrm{pCO} 2$ values higher than non-navigational approaches there was no influence in univariate and multivariate analysis of blood gas parameters in regards to a potential risk scenario as described above by JV in comparison to the JV with non-navigational purposes. In other words: JV tends to increase modestly over time $\mathrm{pCO} 2$ in general but in univariate and multivariate analysis navigational purposes as described above (with intermittend low frequency ventilaton / apnea) do not enclose an additional risk.

IV) In contrast to the modest changings of $\mathrm{pCO} 2$ and $\mathrm{pH}$ in general there is a clear and highly significant observation that JV raises definetly $\mathrm{pO} 2$ enormously: Oxygenation is under JV no problem in any setting.

VI) Partly in contrast to univariate analysis, the multivariate analysis showed that

1 lung diseases play a crucial role in the ventilation effect irrespective of navigational purposes,

2 patients with a lung disease usually have a heart disease which may affect their ventilation,

3 in the group with lung disease the duration of the procedure was the most important factor for conquering the above-mentioned thresholds irrespective of navigational purposes and

4 that the use of navigation is indifferent for the ventilation effects during the procedure.

Over all according to the multivariate analysis duration of intervention is the most decisive factor for ventilation effects in patients with lung disease, followed by history of lung disease and the effect of hypercapnia (pCO2>50 $\mathrm{mmHg}$ ). The longer the intervention is, the more is the risk to develop high $\mathrm{pCO}_{2}$. According to our dataset this occurs most probably when more than 42.5 minutes have been elapsed after intervention. According to our data we can speculate that there is no difference in risk of harming a patient when applying nasal jet-ventilation for navigational purposes for all three parameters although we apply periods of less CO2-clearance due to navigational purposes. In nasal jet ventilation the application of relaxation is dispensable so that the presence of an anesthesiologist is not required. Moreover; there is no correlation between the different comorbidities, lesion, diagnostic tools, BMI, age and sex: The use of nasal SHFJV is safe for different kind of interventions.

\section{Competing Interests}

The authors have declared that no competing interest exists.

\section{References}

1. Scheuermann-Freestone M, Freestone NS, Langenickel T, Hohnel K, Dietz R, Willenbrock R. A new model of congestive heart failure in the mouse due to chronic volume overload. European journal of heart failure. 2001; 3: 535-43.

2. Leiter R, Aliverti A, Priori R, Staun P, Lo Mauro A, Larsson A, et al. Comparison of superimposed high-frequency jet ventilation with conventional jet ventilation for laryngeal surgery. British journal of anaesthesia. 2012; 108: 690-7. doi:10.1093/bja/aer460.

3. Bohn D. The history of high-frequency ventilation. Respiratory care clinics of North America. 2001; 7: 535-48.

4. Oulton JL, Donald DM. A ventilating laryngoscope. Anesthesiology. 1971; 35: 540-2.

5. Norton ML, Strong MS, Vaughan CW, Snow JC, Kripke BJ. Endotracheal intubation and Venturi (jet) ventilation for laser microsurgery of the larynx. The Annals of otology, rhinology, and laryngology. 1976; 85: 656-63. doi:10.1177/000348947608500516.

6. Smith RB, Babinski M, Petruscak J. A method for ventilating patients during laryngoscopy. The Laryngoscope. 1974; 84: 553-9. doi:10.1288/00005537-197404000-00006.

7. Jonzon A, Oberg PA, Sedin G, Sjostrand U. High frequency low tidal volume positive pressure ventilation. Acta physiologica Scandinavica. 1970; 80: 21A-2A. doi:10.1111/j.1748-1716.1970.tb04845.x.

8. Heijman K, Heijman L, Jonzon A, Sedin G, Sjostrand U, Widman B. High frequency positive pressure ventilation during anaesthesia and routine surgery in man. Acta anaesthesiologica Scandinavica. 1972; 16: 176-87.

9. Barth L. [Therapeutic use of diffusion breathing in bronchoscopy]. Der Anaesthesist. 1954; 3: 227-9.

10. Aloy A, Schachner M, Spiss CK, Cancura W. [Tube-free translaryngeal superposed jet ventilation]. Der Anaesthesist. 1990; 39: 493-8.

11. Sutterlin R, Priori R, Larsson A, LoMauro A, Frykholm P, Aliverti A. Frequency dependence of lung volume changes during superimposed high-frequency jet ventilation and high-frequency jet ventilation. British journal of anaesthesia. 2014; 112: 141-9. doi:10.1093/bja/aet260.

12. Minana G, Nunez J, Banuls P, Sanchis J, Nunez E, Robles R, et al. Prognostic implications of arterial blood gases in acute decompensated heart failure. European journal of internal medicine. 2011; 22: 489-94. doi:10.1016/j.ejim.2011.01.014.

13. Hohenforst-Schmidt W, Banckwitz R, Zarogoulidis P, Vogl T, Darwiche K, Goldberg E, et al. Radiation Exposure of Patients by Cone Beam CT during Endobronchial Navigation - A Phantom Study. Journal of Cancer. 2014; 5: 192-202. doi:10.7150/jca.8395.

14. Zaric B, Stojsic V, Carapic V, Kovacevic T, Stojanovic G, Panjkovic M, et al. Radial Endobronchial Ultrasound (EBUS) Guided Suction Catheter-Biopsy in Histological Diagnosis of Peripheral Pulmonary Lesions. Journal of Cancer. 2016; 7: 7-13. doi:10.7150/jca.13081.

15. Huang $H$, Huang $Z$, Wang $Q$, Wang $X$, Dong $Y$, Zhang $W$, et al. Effectiveness of the Benign and Malignant Diagnosis of Mediastinal and Hilar Lymph Nodes by Endobronchial Ultrasound Elastography. Journal of Cancer. 2017; 8: 1843-8. doi:10.7150/jca.19819.

16. Oezkan F, Khan A, Zarogoulidis P, Hohenforst-Schmidt W, Theegarten D, Yasufuku K, et al. Efficient utilization of EBUS-TBNA samples for both diagnosis and molecular analyses. OncoTargets and therapy. 2014; 7: 2061-5. doi:10.2147/OTT.S72974.

17. Zarogoulidis P, Huang H, Bai C, Kosmidis C, Trakada G, Veletza L, et al. Endobronchial ultrasound convex probe for lymphoma, sarcoidosis, lung cancer and other thoracic entities. A case series. Respiratory medicine case reports. 2017; 22: 187-96. doi:10.1016/j.rmcr.2017.08.016.

18. Hohenforst-Schmidt $\mathrm{W}$, Zarogoulidis $\mathrm{P}$, Vogl T, Turner JF, Browning R, Linsmeier $\mathrm{B}$, et al. Cone Beam Computertomography (CBCT) in Interventional Chest Medicine - High Feasibility for Endobronchial 
Realtime Navigation. Journal of Cancer. 2014; 5: 231-41. doi:10.7150/jca.8834. 